\title{
Recent advances of novel technologies for quality consistency assessment of natural herbal medicines and preparations
}

\author{
Xi-Chuan Wei ${ }^{1}$, Bo Cao ${ }^{1}$, Chuan-Hong Luo ${ }^{1}$, Hao-Zhou Huang ${ }^{1}$, Peng Tan ${ }^{2}$, Xiao-Rong Xu', Run-Chun Xu', \\ Ming Yang ${ }^{3}$, Yi Zhang ${ }^{4}$, Li Han $^{1 *}$ and Ding-Kun Zhang ${ }^{1 *}$ (D)
}

\begin{abstract}
Quality consistency is one of the basic attributes of medicines, but it is also a difficult problem that natural medicines and their preparations must face. The complex chemical composition and comprehensive pharmacological action of natural medicines make it difficult to simply apply the commonly used evaluation methods in chemical drugs. It is thus urgent to explore the novel evaluation methods suitable for the characteristics of natural medicines. With the rapid development of analytical techniques and the deepening understanding of the quality of natural herbs, increasing numbers of researchers have proposed many new ideas and technologies. This review mainly focuses on the basic principles, technical characteristics and application examples of the chemical evaluation, biological evaluation methods and their combination in quality consistency evaluation of natural herbs. On the bases of chemical evaluation and clinical efficacy, new methods reflecting their pharmacodynamic mechanism and safety characteristics will be developed, and gradually towards accurate quality control, to achieve the goal of quality consistency. We hope that this manuscript can provide new ideas and technical references for the quality consistency of natural drugs and their preparations, thus better guarantee their clinical efficacy and safety, and better promote industrial development.
\end{abstract}

Keywords: Natural herbal medicines, Quality consistency assessment, Chemical evaluation, Biological evaluation, Chemical-biological integration evaluation

\section{Background}

Natural herbal medicines are important complementary and alternative drugs in the world, which has played a crucial role in the development of human beings. At present, they are still the indispensable medical and health resources in China, Japan, Korea, India and other Asian countries. However, owing to differences in genetic backgrounds, geographical origins, planting environment, cultivation techniques, harvesting time, processing methods, exogenous impurities, and so on, the quality

\footnotetext{
*Correspondence: hanliyx@163.com; 465790643@qq.com

1 School of Pharmacy, State Key Laboratory of Characteristic Chinese

Drug Resources in Southwest China, Chengdu University of Traditional Chinese Medicine, No. 1066 Avenue. Liutai, Chengdu 611137, China

Full list of author information is available at the end of the article
}

variation of natural medicines was significant [1], which is one of the main differences between natural medicines and chemical medicines.

Quality consistency is one of the basic attributes of medicines. Poor consistency makes it difficult to guarantee the effectiveness of drugs and increases the safety risk [2]. In the past, the quality consistency of natural herbs has not attracted much attention of clinicians, pharmaceutical companies and regulatory authorities. It was not until Dr. Weimar Shupei Pharmaceutical Factory in Germany used blending method to control the consistency of different batches of Ginkgo biloba leaves that pharmaceutical companies realized that the quality consistency of natural medicines with complex chemical composition could also be achieved [3]. Recent years, more and more

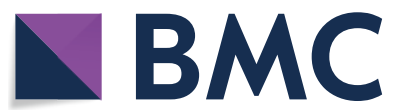

(c) The Author(s) 2020. This article is licensed under a Creative Commons Attribution 4.0 International License, which permits use, sharing, adaptation, distribution and reproduction in any medium or format, as long as you give appropriate credit to the original author(s) and the source, provide a link to the Creative Commons licence, and indicate if changes were made. The images or other third party material in this article are included in the article's Creative Commons licence, unless indicated otherwise in a credit line to the material. If material is not included in the article's Creative Commons licence and your intended use is not permitted by statutory regulation or exceeds the permitted use, you will need to obtain permission directly from the copyright holder. To view a copy of this licence, visit http://creativeco mmons.org/licenses/by/4.0/. The Creative Commons Public Domain Dedication waiver (http://creativecommons.org/publicdomain/ zero/1.0/) applies to the data made available in this article, unless otherwise stated in a credit line to the data. 
attention has been paid to the quality consistency of natural herbs both in China and in other countries, especially in the process of industrial development [4]. For instance, Compound Danshen Dropping Pills, a modern Chinese medicine widely used in China for the treatment of cardiovascular diseases, were asked to provide measures to ensure product quality consistency between batches during the FDA registration process. In 2014, the FDA released "Guidance for Industry: Botanical Drug Products". The guidelines state clearly that the most important point in the development of botanical drugs is ensuring that the quality and therapeutic effects of batches of drugs sold on the market are consistent $[5,6]$. The latest guidelines issued by China Food and Drug Administration for the development of traditional medicines in 2018 also encourage the homogenization of medicinal materials to ensure the stability of the quality of preparations.

For the chemical medicines, the compositions are well defined, the quality consistency is generally determined by the measurement of in vitro dissolution curves, in vivo bioavailability $[7,8]$. But for multi-component chemical drugs, especially natural herbs, the chemical composition is usually complex and the main active ingredients are not clear [9]. The main problems are mainly in the preparation process, composition analysis, quality research and so on. Under these conditions, how can we evaluate the quality consistency scientifically? The FDA guidelines point out that for drugs that cannot be fully evaluated by chemical methods, biological evaluation methods can be used. Among these ones, two botanical drugs have been approved for marketing, of which one is the green tea extract Veregen and the other is the resin extract Mytesi from the South American croton or dragon's blood tree.

In view of the emergence of large number of methods for evaluating the quality consistency of natural herbal medicines in recent years, this manuscript mainly reviewed chemical methods, biological methods and their combination (Fig. 1). We hope that it can help to insight the nature of the quality of natural herbal medicine, explore scientific evaluation methods of quality consistency, and lay a foundation for the industrialization and clinical application of natural herbal medicine.

\section{Evolution of the concept of quality consistency assessment for natural medicines}

The quality of natural herbs is fluctuating. In the age of lack of medical care, the volatility of quality does not affect the clinical treatment of herbal medicine to a large extent. After all, the first thing that needs to be protected is the accessibility of drugs [10]. However, with

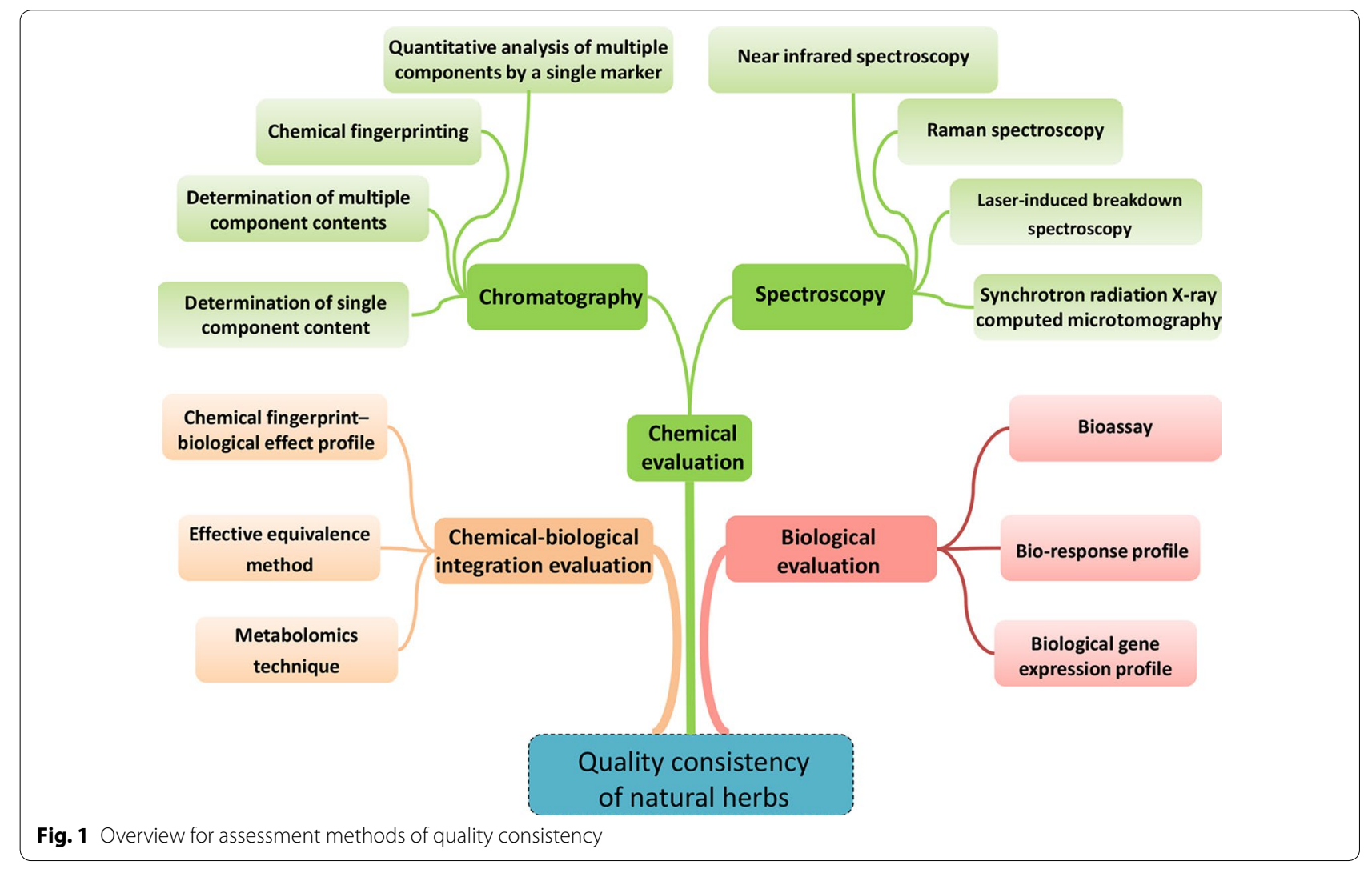


the great enrichment of social materials and the rapid improvement of medical standards, the quality fluctuation of herbal medicines has become a defect that cannot be ignored. The stable and controllable quality is the basic attribute of the drug. The excessive quality fluctuation makes the efficacy of the herbal medicine difficult to evaluate effectively, and even causes safety risks. The industrialized products produced are difficult to stabilize.

The concept of quality consistency evaluation of natural herbal medicines is to guide the development of conformity assessment methods to achieve chemical homogeneity or bioequivalence of natural herbs within a certain range. The evolutionary development process of the method for assessing the quality consistency of natural herbal medicines is essentially a process of deepening the understanding of the quality attributes of natural herbs and the scientific connotation of treatment [11].

Initially, the quality consistency assessment method of natural herbs is based on the quality control concept of chemical drugs, starting from the consistency of the content of a single component. With the deepening of the research on the effective substances of natural herbs, the characteristics of the multi-component interaction of natural herbs have been found, and the object of chemical consistency evaluation has also evolved from a single component to a multi-component content and the similarity or characteristic profile of the overall fingerprint. In fact, there is a certain deficiency in the consistency of multi-component content or the similarity of the overall fingerprint. The defect of consistency of multi-component content is that the actual operation process can hardly guarantee the complete consistency of each indicator component of different batches of natural medicine, unless a single target compound is artificially added without calculating the cost. Some studies have shown significant chemical typing of natural medicines from different sources. For example, rhubarb from different habitats has rhein and rhubarb phenolic forms [12]. At present, fingerprint similarity evaluation is considered as a relatively complete method, but its shortcomings are obvious. First, some components do not have UV absorption, such as polysaccharides, proteins, etc.; Second, the similarity of fingerprints is mainly determined by the high abundance peaks in the chromatogram, which weakens the contribution of some high-activity, low-content chromatographic peaks [13]. For example, the antiviral active ingredient $(\mathrm{R}, \mathrm{S})$-Goitrin in the Radix isatidis is only about $0.02 \%$, which is much lower than the content of adenosine and other components [14]. The fluctuation of the content of $(\mathrm{R}, \mathrm{S})$-Goitrin can hardly affect the similarity evaluation results of the fingerprint. Combining the advantages and disadvantages of these two methods, the consistency evaluation method of fingerprint qualitative and active component quantitative double check is further formed, which not only monitors the overall contour but also individual components.

However, at the practical application level, various operability, time limit, and data analysis requirements have driven a new batch of technologies. Initially, in order to achieve the consistency evaluation under the condition of lack of standard materials, quantitative analysis of multiple components by a single marker (QAMS) was developed [15].

Due to the slow speed and low throughput of traditional chromatographic and mass spectrometry, it is impossible to monitor online. Chemical consistency evaluation gradually adopts technologies with fast, high efficiency and non-destructive advantages, such as Nearinfrared spectroscopy (NIRS), Raman spectroscopy and Laser-induced breakdown spectroscopy (LIBS) and so on [16-18]. Especially, NIRS has played an important role in the online monitoring and consistency assurance of herbal industrial products, achieving a more general industrial application. In order to solve the cumbersome characteristics of chemical analysis, considering the overall characteristics of natural herbal medicines, some physical parameters, such as surface tension, $\mathrm{pH}$, conductivity, viscosity, etc. [19]. It is also used for the consistency evaluation of herbal medicines by establishing a correlation model between physical parameters and chemical composition. This model is used in the industrial extraction of herbal medicines because these parameters are extremely easy to measure, analyze quickly, and regulate in time. Owing to the tremendous advances in chemical analysis, chemical evaluations often yield large amounts of even large amounts of chemical information. The data of consistency evaluation needs to be combined with principal component analysis, cluster analysis, partial least squares discriminant analysis and other chemometric methods to reduce the dimensionality, visually reflect the difference in quality consistency, and identify the key impact factors.

However, pharmacological activity is the core value of natural herbs. Although the chemical consistency-based quality consistency assessment method has made great progress, it still cannot answer the biological consistency. Especially, does the chemical consistency information obtained under specific conditions represent the consistency of biological effects; whether the volatility of chemical information indicates an inconsistency in biological effects. In fact, natural herbs are a complex system of chemical composition, and the dose-effect relationship is not clear or exists only in a specific concentration range. As a result, the concept of assessing the consistency of the activity of natural herbs through bioassays has received increasing attention. Bioassays are 
essentially quantitative pharmacology, which determines that test results are highly correlated with selected test models. The detection model can be human, whole animal, ex vivo tissues and organs, cells, organelles, bacteria, and even enzymatic reactions in vitro [11]. Generally, the more the test is completed at the overall level, the closer the result is to the actual efficacy of the drug, the less false positives, but the weaker the operability, the more difficult the data processing. At the same time, bioassays for consistency assessment must meet the technical requirements of quantitative analysis. From the aspects of method accessibility, analysis accuracy, speed, etc., it is a better choice to select carriers such as cells, bacteria or in vitro methods.

In addition to bioassays, bio-response profiles, biological gene expression profiles, biomarkers, etc. have been developed, taking into the complexities of biological reactions, aging changes, and dose-effect changes. In order to solve the flux problem of bioassay and increase the analysis rate, technologies such as biochips have been developed.

In order to solve the problem of the overall contribution of multi-component activity and content in chemical evaluation, some scholars have proposed the concept of effect component index, which is essentially a method for determining multi-component content based on activity correction $[20,21]$. The technical advantages of high chemical precision, good popularity and bioassay associated activity are comprehensively utilized. On this basis, in order to give the actual pharmacological significance of the data, to facilitate the consistency guarantee operation such as blending batches, and to draw on the concept of explosive equivalent, the overall activity results of multiple components are converted into specific equivalent data of a single standard substance [22]. In addition, in response to the consistency assessment of toxic herbs, injections, etc., a combination of various chemical evaluation methods and biological evaluation methods has been successively derived.

From above, natural herbs have formed a multi-evaluation model with qualitative consistency of chemical evaluation, biological evaluation and its combined technology. For specific herbs or preparations, scientific quality conformity assessment methods should be developed based on their characteristics.

\section{Chemical consistency evaluation method}

In 1985, the Chinese Pharmacopoeia began to compile methods for testing the content uniformity of chemical drugs and stipulated that the content uniformity of solid preparations should not vary by more than $15 \%$. However, the confidence coefficients of two tests were 1.8 and 1.45, respectively, in the Chinese Pharmacopoeia and 2.4 and 2.0, respectively, in the United States, Britain, and Japan, which indicated that the reliability of the test method was low [14, 23]. Therefore, in order to promote the modernization of natural herbal medicines, more credible methods of assessment should be adopted.

\section{Chromatographic evaluation techniques}

At present, the main chemical methods used to determine the quality consistency of drugs are chromatographic, including gas chromatography (GC), liquid chromatography (LC) and mass spectrometry (MS). In recent years, ultrahigh-performance liquid chromatography (UPLC) has gradually become popular and has been used in the analysis of the chemical compositions of natural herbal medicines [24].

In the evaluation of the consistency of the quality of natural herbal medicines, chromatography can be combined with MS to qualitatively and quantitatively analyze the composition of natural herbal medicines. The difference in consistency can be visually compared by mass spectrometry imaging [25]. Further, through chemical analysis means, the statistical methods of chemometrics are established, which can more accurately reflect the differences in the composition of natural herbal medicines, and provide a reference for the consistency evaluation of natural herbal medicines.

\section{Determination of single component contents}

Single-component quality assessment is a method used to control the quality of natural herbal medicines by determining the content of one of their effective components. However, natural herbal medicinal preparations are different from chemical drugs. Most chemical drugs only have one component, and the determination of the content of this single component can accurately indicate the consistency of the quality of the drug [26,27].

In the early days, natural herbs reflected their quality consistency by measuring the content of a single ingredient. However, the ingredients of natural herbal medicines are complex, and their effects are the results of the combined effects of various ingredients. Differences in the contents of natural herbal medicinal preparations and the proportions of the ingredients will affect the efficacy of such preparations in clinical applications. Therefore, the quality consistency standards for natural herbal medicinal preparations have been extended to include quantitative determination methods based on multiple components and indices.

\section{Determination of multiple component contents}

The determination of multiple component contents is a method for controlling the quality of natural herbal medicinal preparations by measuring the contents of 
multiple active ingredients of natural herbal medicines or preparations. Tang et al. [28] used an HPLC-MS/MS method to identify the appropriate solvent and extraction method, determined the contents of 14 toxic and effective components in 29 batches of aconite formula granules, and assessed the consistency of their quality by a variety of chemometric methods.

Compared with the determination of a single component, the multi-component measurement is based on the comparison of multiple target components selected by it, which highlights the overall concept and makes a more scientific evaluation of natural herbs and their preparations. With the increase in the number of natural herbal medicines, traditional methods of assessment based on single components will gradually be replaced by the determination of multiple active ingredients.

\section{Chemical fingerprinting}

Chemical fingerprinting is a feasible method of confirming the authenticity of natural herbal medicines and assessing the consistency of their quality. Via the analysis of known and unknown components, it can fully indicate the overall situation of the complex system of natural herbal medicines [29]. At present, there are many examples of the application of chromatographic fingerprint method to determine the consistency of quality, and usually combined with chemometric methods for analysis, comprehensively reflecting the overall quality of natural herbs [30, 31]. Wang et al. [32] compared four kinds of chromatographic fingerprints of 71 batches of Xin-KeShu using similarity analysis combined with hierarchical cluster analysis and finally proposed an effective strategy for assessing the consistency of their quality.

In recent years, Sun et al. have proposed a multi-component quantitative fingerprint technology that combines multi-wavelength measurement and metrological analysis to prove and verify the consistency of the quality of natural Chinese herbal medicine [33-38].

Compared with multi-component measurement, chemical fingerprints more comprehensively reflect the overall substance of natural herbs. If the active ingredients of herbs are not clear, chromatographic fingerprints can be provided to prove the consistency of product quality. Combined with fingerprint pharmacodynamics, the quality of natural herbs can be truly combined with their efficacy, which helps to clarify their mechanism of action.

\section{Quantitative analysis of multiple components by a single marker}

Quantitative analysis of multiple components by a single marker (QAMS) achieves the simultaneous determination of many other components of natural herbal medicines using a simple and easily measured component. It not only optimizes the detection of drugs but also dispenses with the use of standard substances and is a feasible method for assessing the effectiveness and internal quality of natural herbal medicines [39]. Li et al. [40] used HPLC to establish the fingerprint of Achyranthes bidentata Blume and, in combination with QAMS, analyzed the similarity and hierarchical clustering and assessed the quality of 18 batches of $A$. bidentata. The results show that there is no significant difference in the results of multi-component quantitative analysis established by the single-marker method and the external standard method, which can effectively determine the consistency of drug quality.

In the absence of chemical reference materials, the combination of chemical fingerprints and QAMS can still accurately and reliably determine the content of multiple ingredients in natural medicines, and further assess the consistency of their quality.

Chemical methods of assessment are still among the mainstream methods for assessing the consistency of quality (Fig. 2) (Table 1). Their advantages are that the methods are mature, the processes are simple, and the contrast that they provide is strong. However, their shortcomings are also obvious in that they require large number of preprocessing operations, which are timeconsuming and laborious, and the use of reference substances is also extensive. The chromatographic evaluation method is mainly based on off-line detection methods, and is a detection method for production results. It cannot monitor the fluctuation of the quality index of natural herbs in the production process in real time, so it is impossible to control the quality consistency between batches of traditional Chinese medicine products. Therefore, in the process of producing pharmaceutical preparations in industry, to be able to control the quality of natural herbal medicines and their preparations online and in real time, methods for the assessment of the consistency of the quality of natural herbal medicines began to adopt spectral evaluation techniques.

\section{Spectral evaluation techniques}

Spectroscopic technology can quickly analyze the comprehensive properties of the samples, and design, control and analyze the production and processing process by measuring the key quality, quality and characteristics of the original medicinal materials and the materials in processing in real time. Similarly, the spectrum evaluation technology is like the chromatography technology. There are three levels in the development process: firstly, the single element content is analyzed by the spectrum technology, then it gradually develops into multi-element analysis, and finally it evolves into 


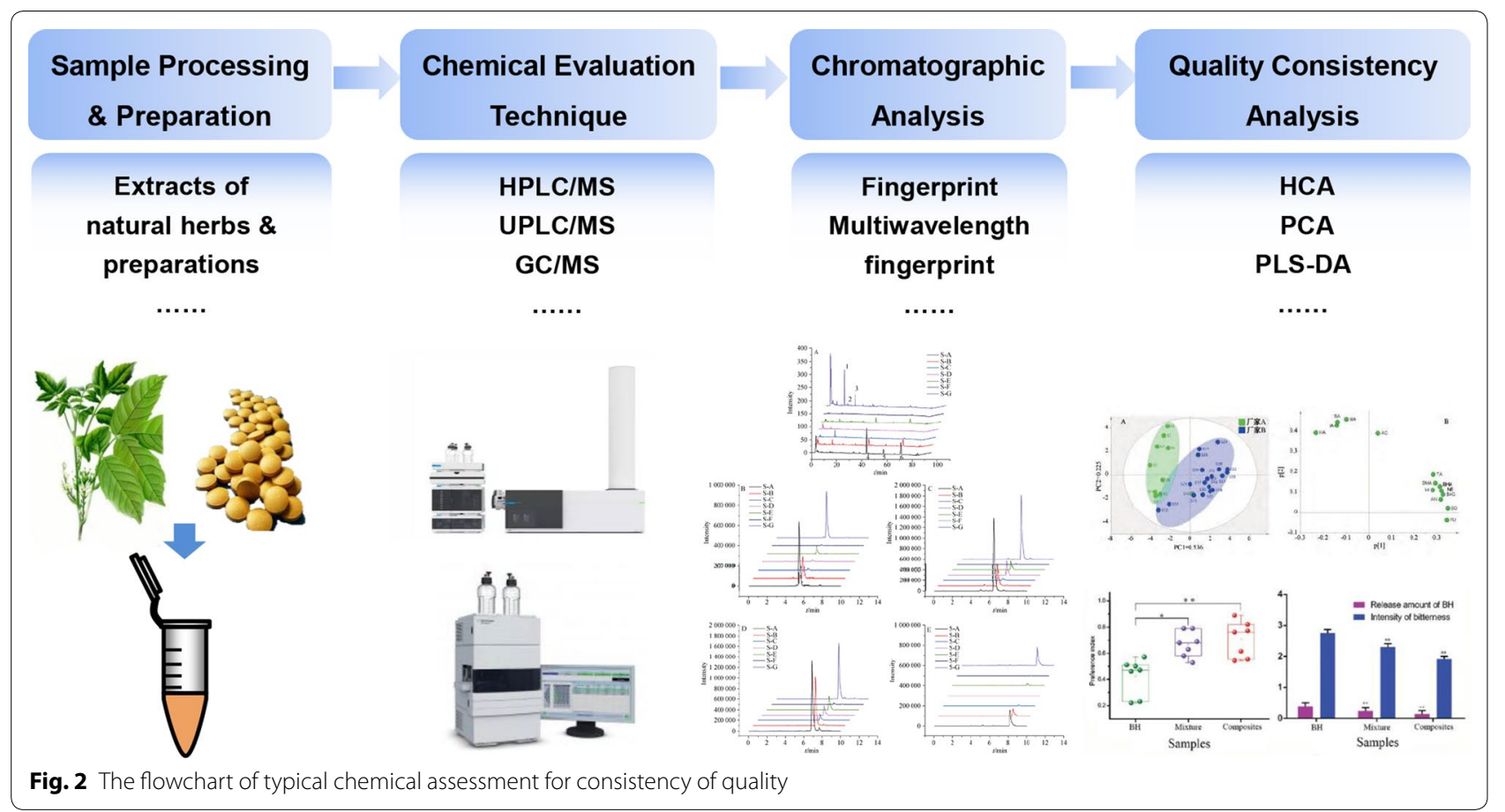

a comprehensive analysis of the overall elements of the sample. This article mainly briefly introduces the application of the following several spectral techniques in quality consistency evaluation.

\section{Near-infrared spectroscopy}

Near-infrared (NIR) spectroscopy is an advanced green process analysis technique that relies on computer assistance to achieve rapid analysis and testing. In comparison with traditional analysis techniques, it has many advantages, such as high efficiency, rapidity, low energy consumption, and avoiding sample pretreatment, pollution, and destruction of the sample $[57,58]$. The optical principles of NIR spectroscopy are mainly transmission spectroscopy and reflection spectroscopy. Characteristic information on hydrogen-containing groups in organic molecules in a sample can be obtained by analyzing the sample with an NIR spectrometer. A mathematical model of the sample can then be established using stoichiometry software, so that the relevant information can be obtained quickly [59-61]. In recent years, NIR spectroscopy has become popular and has been applied in many fields such as the petroleum sector, agriculture, industry, and medicine. It has also been applied in the field of natural herbal medicines [62-64]. Much research has shown that NIR spectroscopy has a wide range of application and can directly and quantitatively analyze original and compound natural herbal medicines and natural herbal medicinal preparations. Moreover, fiber optic probes can be used to achieve comprehensive continuous online monitoring of the production processes of natural herbal medicines $[65,66]$. NIR spectroscopy can effectively enable the control of the consistency of the quality of natural herbal medicines (Fig. 3). Yang et al. [67] used NIR spectroscopy combined with multivariate statistical process control techniques, such as principal component analysis (PCA) or partial least-squares analysis, to study changes in quality during the extraction of honeysuckle extract from multiple batches. NIRS technology can monitor the changes of natural drugs in the production process online in real time, and then establish a model through chemometrics to analyze the spectral data, which is of great significance for improving the quality control level of modern natural herbal production $[68,69]$.

Near-infrared chemical imaging (NIR-CI) is an extension of NIR spectroscopy. By combining traditional visualization imaging with NIR spectroscopy, simultaneously analyzing the spectral and spatial distributions of a sample, visualizing its components, and finally forming a visualized image, it is an effective method for assessing the consistency of the quality of natural herbal medicines and their preparations [70-73]. Wang et al. [74] studied the relationship between the hardness and uniformity of different dispersible Yinhuang tablets using NIR-CI and used stoichiometry to measure the spatial uniformity of the tablet components. Finally, by the quantitative analysis of agglomerates of polyvinylpolypyrrolidone, the law governing the hardness and uniformity of the spatial 
Table 1 Quality consistency evaluation with chemical evaluation technology

\begin{tabular}{|c|c|c|c|}
\hline Sample & Detection method & Analytical method & References \\
\hline Salvia miltiorrhiza Bunge & $\begin{array}{l}\text { Direct analysis in real time mass spectrometry } \\
\text { (DART-MS) }\end{array}$ & PCA, Hotelling T(2) and dmodx & [24] \\
\hline Hydrocortisone & HPLC-MS & Pharmacopoeial standards & [26] \\
\hline Low-dose drug products & UPLC & Response surface methodology & [27] \\
\hline Aconite formula granules & HPLC-MS/MS & $C A, P C A, P L S-D A$ & [28] \\
\hline Melissa officinalis L. & HPLC fingerprint & SA, PCA & [29] \\
\hline Shenmai injection & HPLC fingerprint & PCA, Hotelling $T(2)$ and $d m o d x$ & [30] \\
\hline Shaoyao-Gancao decoction & LC-MS/MS, HPLC fingerprint & $\mathrm{SA}, \mathrm{HCA}, \mathrm{PCA}$ & [31] \\
\hline Xin-Ke-Shu (XKS) tablets & Four types of chromatographic fingerprint & SA, HCA, Mahalanobis distance & [32] \\
\hline Niuhuang Jiedu Pills & Integrated quantitative fingerprint & Wavelength Fusion Profiling, HCA, PCA & [34] \\
\hline Compound Bismuth Aluminate tablets & HPLC multi-wavelength fingerprint & $\begin{array}{l}\text { Simple quantified ratio fingerprint method, } \\
\text { PLSR }\end{array}$ & [35] \\
\hline Compound liquorice tablets & $\begin{array}{l}\text { Multi-wavelength fusion HPLC fingerprints, UV } \\
\text { fingerprint, UHPLC-ESI-Q-TOFMS }\end{array}$ & $\begin{array}{l}\text { Averaged linear quantified fingerprint method, } \\
\text { flow injection analysis }\end{array}$ & {$[36]$} \\
\hline Liuwei Dihuang Pills & $\begin{array}{l}\text { HPLC five-wavelength overall fused finger- } \\
\text { prints, UV spectroscopic fingerprint }\end{array}$ & SA, PLSR & {$[37,38]$} \\
\hline Achyranthes bidentata Blume & HPLC fingerprint, QAMS & $\mathrm{SA}, \mathrm{HCA}$ & [40] \\
\hline Fufanggancao tablets & Quantitative HPLC fingerprint & SA & [41] \\
\hline Ginkgo biloba leaves & UPLC-MS/MS & SA & [42] \\
\hline Banxia Baizhu Tianma decoction & HPLC fingerprint & PCA, SA, information entropy & [43] \\
\hline Kudiezi injection & $\begin{array}{l}\text { HPLC-UV fingerprints, GC-MS fingerprints, } \\
\text { HPIEC fingerprints }\end{array}$ & $\mathrm{SA}, \mathrm{HCA}$ & [44] \\
\hline Cicadae Periostracum & UPLC-QTOF-MS/MS & SA & [45] \\
\hline Xuesaitong Dropping Pills & UPLC fingerprint & SA, PCA, OPLS-DA & [46] \\
\hline Desmodium styracifolium & HPLC fingerprint & SQFM & [47] \\
\hline Xiaojin Pills & HPLC-MS/MS & PCA, HCA & [48] \\
\hline Ganoderma lucidum & $\begin{array}{l}\text { HPTLC fingerprints, GC-MS fingerprints, PACE, } \\
\text { HPSEC-meid }\end{array}$ & $\mathrm{HCA}$ & [49] \\
\hline Yinqiaojiedu tablets & Three wavelength fusion HPLC fingerprint & SQFM, PCA & {$[50]$} \\
\hline Guava leaf & HPLC-TOF-ESI-MS Fingerprint & $\mathrm{HCA}, \mathrm{PCA}$ & [51] \\
\hline Sambucus nigra L. & HPLC fingerprint & HCA, PCA & {$[52]$} \\
\hline Hyangsapyeongwisan & UPLC fingerprint & SA & [53] \\
\hline Liuwei Dihuang Pills & HPLC fingerprint & SA, PCA & [54] \\
\hline Qingfu Guanjieshu capsules & HPLC fingerprint & SA & {$[55]$} \\
\hline Yiqing preparations & HPLC fingerprint & SA & {$[56]$} \\
\hline
\end{tabular}

distribution of dispersible Yinhuang tablets was revealed. Zhang et al. [75] adopted NIR DRS, established a mathematical model after first-order derivative and multiplicative scattering correction treatment and compared differences in the content of berberine in the production process that represented different levels of compatibility, which provided a basis for online monitoring of the production of natural herbal medicines.

NIRS is currently a popular technique for determining the quality of natural herbal medicines and represents a fast and effective method for assessing consistency of quality. NIRS can be applied to all key links in the production process of natural herbs and their preparations, such as extraction, concentration, alcohol precipitation, mixing, etc., to achieve quality control in the production process of drugs. As mentioned previously, it needs to be modeled in combination with chemometrics, but the model suffers from a certain amount of one-sidedness. Therefore, a focus of future research will be the analysis of spectra and direct examination of the resulting data [76]. Similarly, the current NIRS technology still has limitations such as high detection limit and unstable response value. The solution of these problems will accelerate the application of NIRS technology in the actual production process of natural medicine. 


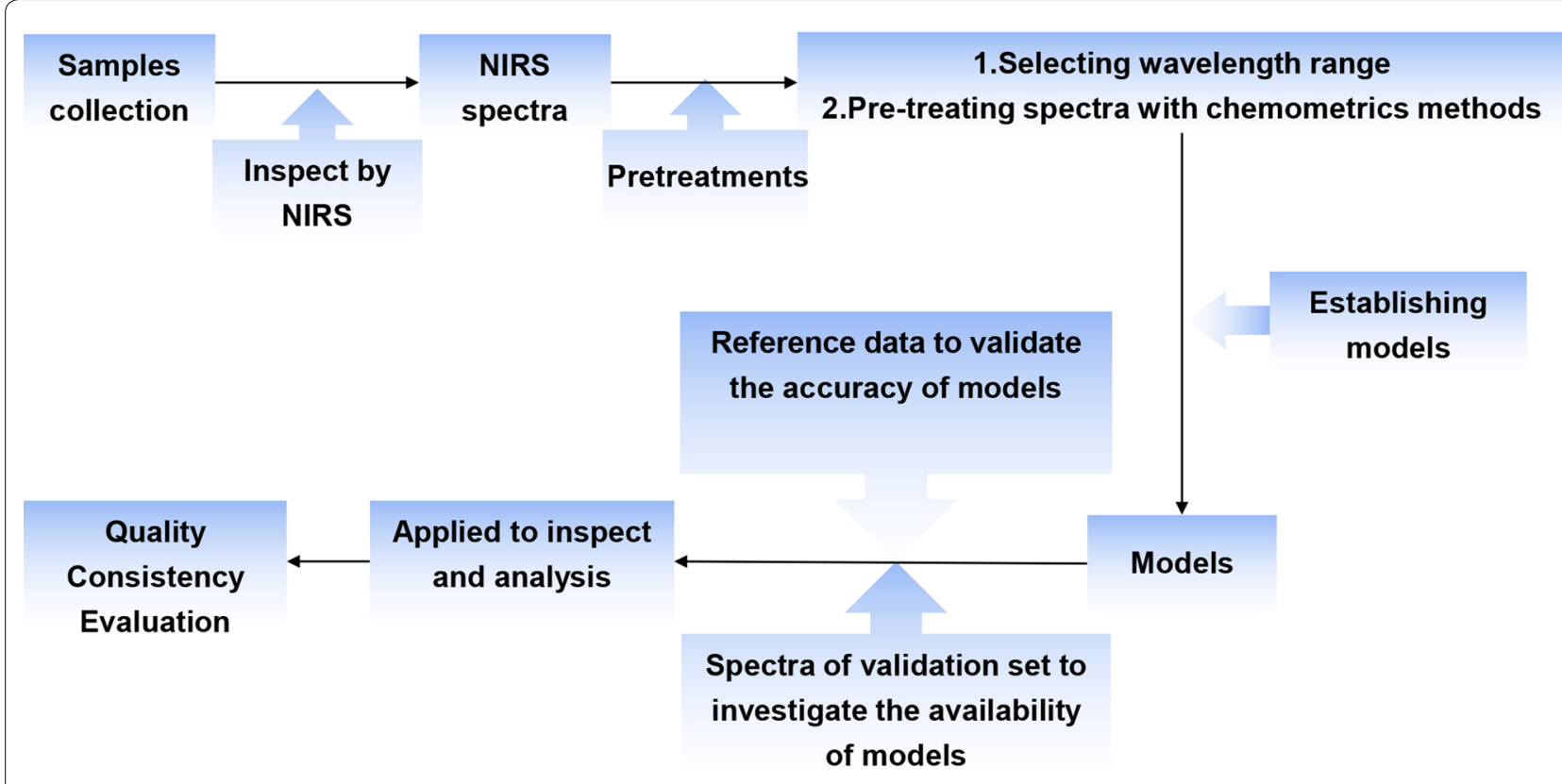

Fig. 3 The basic process of NIRS for assessment of consistency of quality

\section{Raman spectroscopy}

Raman spectroscopy is a fast and lossless technique for process analysis that can provide information on the frequency and intensity of molecular vibrations and can thus be used to analyze the structures and properties of substances. In recent decades, Raman spectroscopy has been widely used in the fields of polymers, pharmaceuticals, biological treatment, and biomedical analysis [77]. To some extent, Raman and NIR spectroscopy can complement each other in the analysis of molecular structures. Infrared spectroscopy records the transmission spectra of samples, and its principle is the change in the dipole moment; Raman spectroscopy records the emission spectra of samples, and its mechanism lies in the change in molecular polarizability. Both techniques can be used for the analysis of organic compounds, but for inorganic substances, especially oxides, it is difficult to obtain a complete spectrum by infrared spectroscopy, and the spectral bands are very wide, whereas the Raman spectral bands are very sharp. The effect of Raman spectral scattering is weak, and enhancement methods are often used in practical applications, such as surfaceenhanced Raman spectroscopy, high-temperature Raman spectroscopy, resonance Raman spectroscopy, confocal Raman microscopy, Fourier transform Raman spectroscopy, and combinations with other techniques [78]. Modern portable and handheld Raman spectrometers are widely used in drug quality screening to detect low levels of substances or in combination with appropriate stoichiometric methods to distinguish compounds with similar structures and minimal spectral differences [79-82].

Raman spectroscopy has been widely used in the analysis of the compositions of pharmaceutical preparations and has been applied in the determination of the quality of mineral drugs in natural herbal medicine [83]. However, at present, the main application range of Raman spectroscopy is rapid detection, detecting the difference between the presence or absence of samples. For quantitative analysis in the process of drug production, Raman spectroscopy also needs to develop a corresponding model in combination with chemometrics. It is feasible to use the online Raman spectroscopy analysis technology to detect the production process of natural drugs, but the application of Raman spectroscopy in this area is still relatively small. How to design a stable and effective model is a matter of concern to researchers.

\section{Laser-induced breakdown spectroscopy}

Laser-induced breakdown spectroscopy (LIBS) is a form of atomic emission spectroscopy that involves the generation of a plasma using a laser as the excitation source. It is used for the rapid determination of the elemental contents and concentrations of materials by physical means (Fig. 4). Over the past two decades, LIBS has become a recognized and valuable analytical spectroscopic technique for the qualitative or quantitative analysis of the elemental properties of any type of sample [84]. With the 


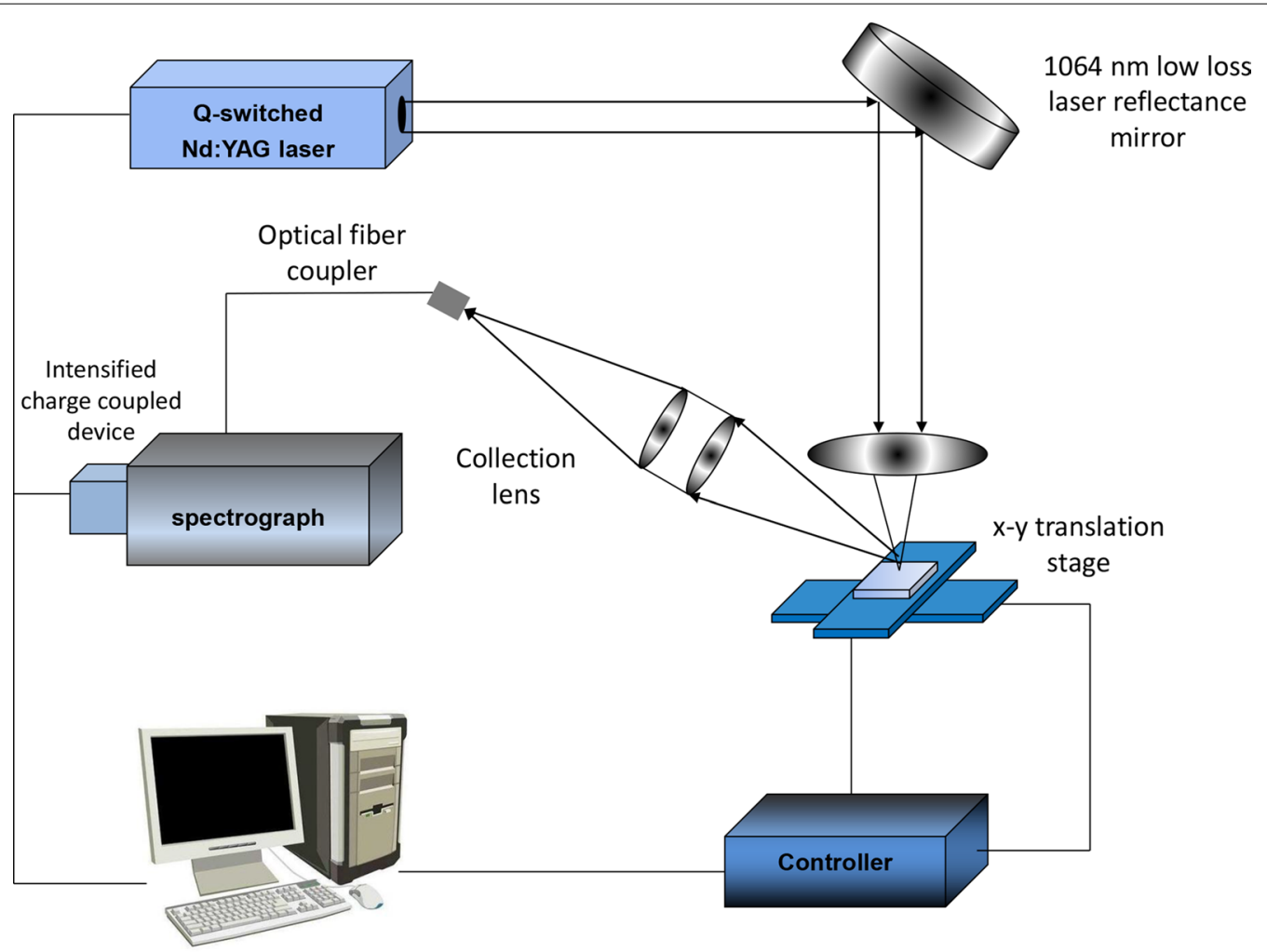

Fig. 4 Schematic diagram of LIBS experimental device

development of optical technology, laser sampling and detection have gradually become mature. LIBS has been applied in industrial, agricultural, and pharmaceutical environmental monitoring, archeology, remote sensing, and other fields, as well in the quality control of natural herbal medicines [85]. By analyzing the distribution and quantitatively analyzing related elements in a drug, the consistency of the quality of the drug can be judged according to its elemental content [86]. Liu's team has done a lot of research on LIBS technology in the rapid detection of natural drugs [87-91]. Wang et al. [92, 93] used LIBS to determine the contents of copper and lead in Rhizoma Chuanxiong and established a model in combination with multiple linear regression. Using LIBS in combination with PCA and an artificial neural network to analyze and identify the elemental compositions of Radix Angelicae Dangshen and Polygonum cuspidatum roots from different habitats and areas.

LIBS can be used to establish a method for the integral characterization of multiple elemental spectra in the quality control of natural herbal medicines. From the analysis of trace elements in natural herbal medicines in combination with chemometrics, visual data can be quickly obtained, and hence the consistency of the quality of different batches of natural herbal medicines and their preparations can be assessed [94]. At present, compared with near infrared spectroscopy and Raman spectroscopy, the sensitivity and accuracy of LIBS still need to be improved, but some characteristics of LIBS make it more suitable for elemental analysis. It is recommended to use double pulsed LIBS, magnetic confined LIBS and spark discharge LIBS to improve the sensitivity and accuracy of LIBS.

\section{Synchrotron radiation $X$-ray computed microtomography}

$\mathrm{X}$-ray microtomography uses $\mathrm{X}$-ray penetration to scan objects and then uses a computer for image processing to obtain images. It has been widely used for in vivo imaging of plants, insects, animals, and humans [95]. However, ordinary X-ray sources limit its development. Synchrotron radiation X-ray computed microtomography $(\mathrm{SR}-\mu \mathrm{CT})$ uses high-performance synchrotron radiation $\mathrm{X}$-rays as a radiation source to collect threedimensional structural information on samples, which has the advantages of high resolution, high discrimination, rapidity, and non-destructiveness, etc. This technique has unique advantages in the characterization of the structures of solid powders and particles [96, 97]. $\mathrm{Li}$ et al. [98] visualized the internal structures of sustained-release felodipine tablets in the process of drug 
release using $\mathrm{SR}-\mu \mathrm{CT}$, analyzed the surface morphology and changes in the structures of the tablets, and finally showed that SR- $\mu \mathrm{CT}$ is a new method for drug quality control. Wu et al. [99] determined the three-dimensional structure of the release hole in a captopril osmotic pump tablet by SR- $\mu \mathrm{CT}$, observe its distribution clearly.

When SR- $\mu \mathrm{CT}$ is used to study the three-dimensional structures and distributions of solid preparations, it can determine the sizes and distributions of particles in the body of the drug and enable the visualization and quantification of the structure of the preparation. Starting from the structure, it provides a new perspective on the assessment of the consistency of the quality of natural herbal medicines $[100,101]$ (Fig. 5). SR- $\mu C$ T combined with 3D reconstruction, image processing, stereo modeling and quantitative analysis technology can realize the visualization and quantification of the preparation structure from both static and dynamic angles, and accurately quantify the fine structures of different levels. However, due to the requirements of the instrument, the detection object of $\mathrm{SR}-\mu \mathrm{CT}$ is suitable for solid preparations and particle dispersion systems.

In addition to the above several new spectral techniques, there are some more commonly used spectroscopy techniques, such as ultraviolet spectroscopy, fluorescence spectroscopy and so on. The use of these technologies alone is no longer sufficient for current research needs, and is generally used in conjunction with new technologies to evaluate sample quality consistency [102-107]. Each spectral technique has outstanding advantages. However, in view of the current research status, the application of NIRS is higher than the other three spectral technologies from the perspectives of economy, practicality, and operability. Comparison on characteristics of four spectral techniques has been summarized in Table 2.

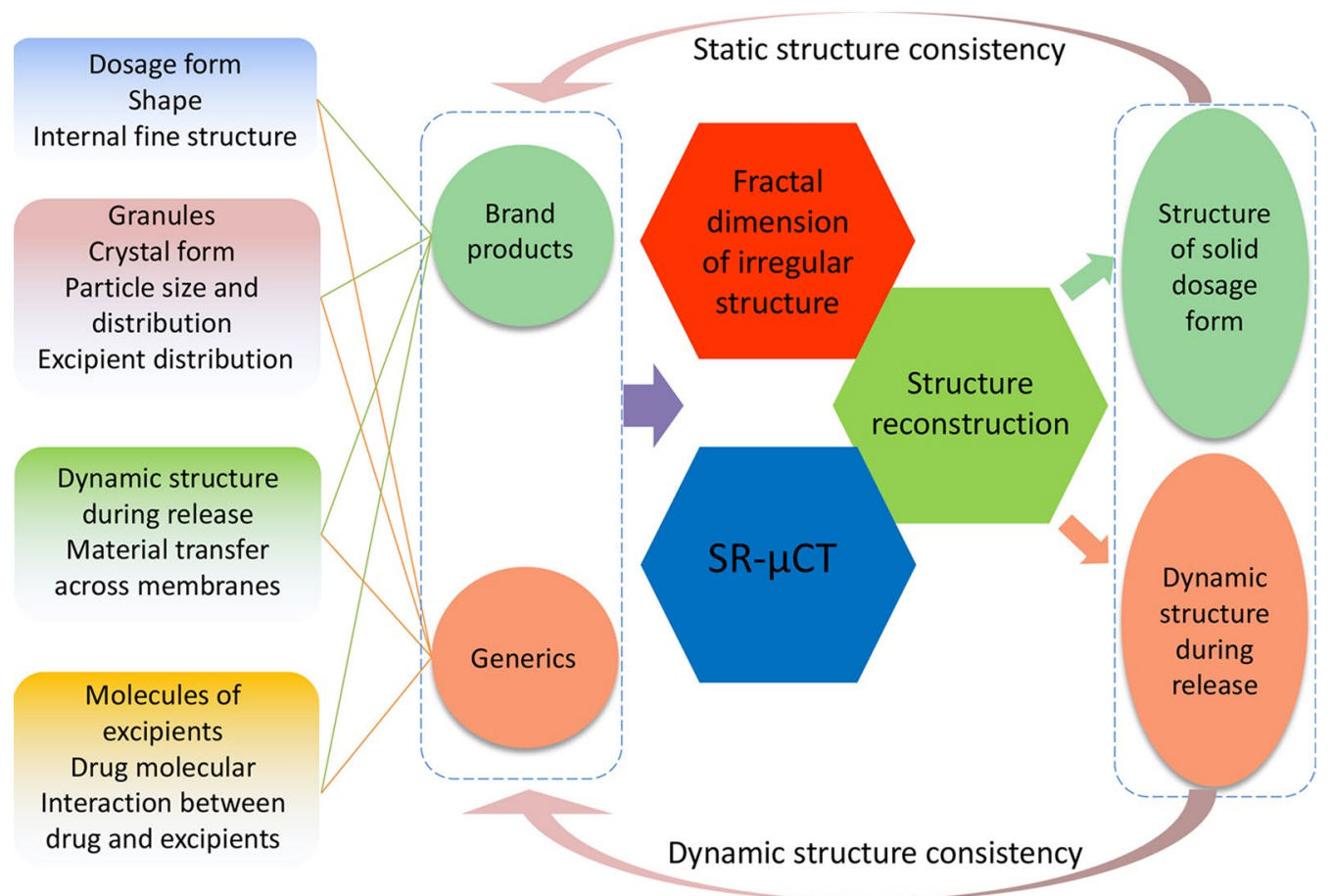

Fig. 5 Road map for structure based strategy for consistency evaluation of dosage forms

Table 2 Comparison of advantages of different spectroscopy techniques

\begin{tabular}{|c|c|c|c|c|c|c|c|}
\hline & Accuracy & Quantitative & Reproducibility & Operability & Safety & Economy & Applicability \\
\hline NIRS & +++ & +++ & +++ & ++++ & ++++ & ++++ & +++++ \\
\hline Raman & ++ & ++++ & ++ & +++ & +++++ & ++ & +++ \\
\hline LIBS & +++ & +++ & ++++ & ++++ & ++++ & +++ & ++++ \\
\hline SR- $\mu \mathrm{CT}$ & ++++ & ++++ & +++ & +++ & ++ & + & ++ \\
\hline
\end{tabular}


By the abovementioned spectral evaluation methods, the chemical consistency of the quality of natural herbal medicines can be determined and differences in consistency can be compared via the contents and distributions of the chemical components of such medicines (Fig. 6) (Table 3).

\section{Biological consistency evaluation methods}

In recent years, the volume of natural herbal medicinal preparations exported from China has been much lower than that of natural herbal medicinal extracts. The main reasons are poor clinical efficacy and the incompleteness of the system for the assessment of bioavailability. Because a high-degree chemical similarity does not equal a bioequivalence. Therefore, the establishment of a complete system for the determination of bioavailability using biological techniques is the key factor in the assessment of consistency of quality and the modernization of natural herbal medicines $[117,118]$.

Biological assessment techniques are based on the biological effects of drugs. Experimental animals are used to obtain their tissues and organs for in vitro tests, microorganisms, cells, and related biological factors are used to determine the efficacy or toxicity of drugs, and thus the quality of drugs is assessed. Biological techniques are new methods for the quality control of natural herbal medicines in addition to chemical assessment of quality and have the advantage of overall controllability of pharmacodynamics [119]. Methods used for the biological assessment of the quality consistency of natural herbal medicines are different from general pharmacological experimental methods. Biological assessment methods for the study of the quality consistency of natural herbal medicines involve not only quantitative pharmacological details such as test design, quantitative indices, interval groupings, and reliability tests but also parameters of pharmaceutical analysis such as linear range, precision, and repeatability.

Biological assessment techniques have the advantage of determining correlative efficacy and are in principle applicable to the assessment of the quality consistency of all the natural herbal medicines. In particular for natural herbal medicines of which the complex contents cannot be determined by physical and chemical methods or the

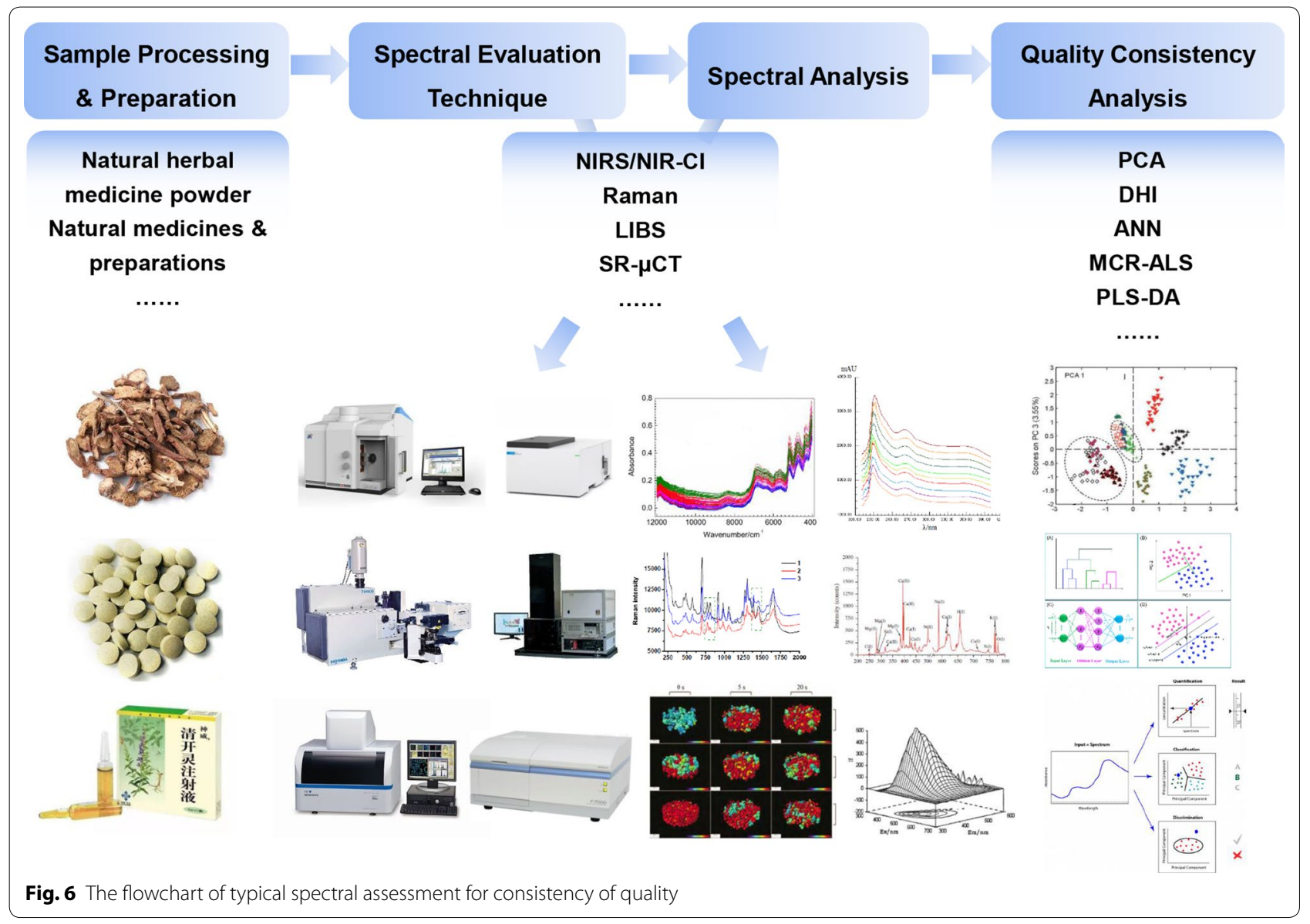


Table 3 Quality consistency evaluation with spectral evaluation technology

\begin{tabular}{|c|c|c|c|}
\hline Sample & Detection method & Analytical method & References \\
\hline Lonicerae japonicae Flos & NIRS & $\begin{array}{l}\text { Multivariate statistical process control } \\
\text { (MSPC) model, PCA }\end{array}$ & {$[67]$} \\
\hline $\begin{array}{l}\text { Cefazolin sodium pentahydrate } \\
\text { Cephathiamidine }\end{array}$ & NIRS & $\begin{array}{l}\text { One-way analysis, factor analysis, cluster } \\
\text { analysis }\end{array}$ & [68] \\
\hline Ramulus cinnamomi & $\begin{array}{l}\text { Microscale thermophoresis } \\
\text { On-line NIR-HPLC }\end{array}$ & Sipls, PLS model & [69] \\
\hline Acetylsalicylic acid tablets & $\mathrm{NIR}-\mathrm{Cl}$ & $\begin{array}{l}\text { Multivariate curve resolution-alternating } \\
\text { least squares }\end{array}$ & [73] \\
\hline Yinhuang dispersible tablets & $\mathrm{NIR}-\mathrm{Cl}$ & $\begin{array}{l}\text { Basic analysis of correlation between } \\
\text { analytes }\end{array}$ & [74] \\
\hline Coptis & NIR diffuse reflectance spectroscopy & MSC, PLS, ANN & {$[75]$} \\
\hline Rukuaixiao tablets & N/MIR diffuse reflectance spectral imaging & Correlation analysis method & [108] \\
\hline Compound Liquorice tablets & $\mathrm{NIR}-\mathrm{Cl}$ & $\begin{array}{l}\text { Basic analysis of correlation between } \\
\text { analytes, PCA }\end{array}$ & [109] \\
\hline Flos Lonicera japonica & $\mathrm{NIR}-\mathrm{Cl}$ & $\begin{array}{l}\text { Basic analysis of correlation between } \\
\text { analytes, moving block macropixel relative } \\
\text { standard deviation }\end{array}$ & [110] \\
\hline Shenzhiling oral Liquid & NIRS & $\begin{array}{l}\text { PLSR, support vector machine regression } \\
\text { (SVMR) }\end{array}$ & [111] \\
\hline Wangbi tablets & NIRS & CARS-PLSR model & [112] \\
\hline Flos Lonicerae Japonicae & NIRS & Synergy interval PLS (Si-GA-PLS) & [113] \\
\hline Acetaminophen, $\mathrm{SiO}_{2}, \mathrm{MCC}, \mathrm{HPMC}$ & Low-resolution Raman spectra & PCA, PLS & [79] \\
\hline Entecavir tablets & $\begin{array}{l}\text { Raman spectra, X-ray powder diffraction, } \\
\text { differential scanning calorimetric }\end{array}$ & Thermo-gravimetric analysis (TGA) & {$[80]$} \\
\hline Atropine sulfate & $\begin{array}{l}\text { LC-MS/MS, Raman-Cl, X-ray powder dif- } \\
\text { fraction }\end{array}$ & SA & {$[82]$} \\
\hline Cinnabar & Surface-enhanced Raman spectrum & Curve fitting & [83] \\
\hline Artemisia annua $\mathrm{L}$. & Laser Raman spectroscopy & Curve fitting & [114] \\
\hline Cornu Caprae Hircus & Raman spectra, & PLS, HCA & {$[115]$} \\
\hline $\begin{array}{l}\text { Brufen, Glucosamine, Glucosamine, Par- } \\
\text { acetamol }\end{array}$ & LIBS & PCA, SIMCA & {$[86]$} \\
\hline Blumea balsamifera DC & LIBS & PCA, PLS-DA model & [87] \\
\hline $\begin{array}{l}\text { Renqing Mangjue, Renqing Changjue, } \\
25 \text {-herb coral Pills, 25-herb pearl Pills }\end{array}$ & LIBS & $\begin{array}{l}\text { National Institute of Standard and Technol- } \\
\text { ogy (NIST) }\end{array}$ & {$[88]$} \\
\hline Juncus effusus L. & LIBS & Elemental microanalysis & [89] \\
\hline An-Gong-Niu-Huang Wan & LIBS & RCCR, MWSD & {$[90,91]$} \\
\hline Ligusticum wallichii & LIBS & Multiple linear regression models & [92] \\
\hline $\begin{array}{l}\text { Angelica pubescens } \\
\text { Codonopsis pilosula } \\
\text { Ligusticum wallichii }\end{array}$ & LIBS & PCA, ANN, LDA & [93] \\
\hline Sustained-release felodipine tablets & $\mathrm{SR}-\mu \mathrm{CT}$ & Data visualization & [98] \\
\hline Captopril osmotic pump tablets & $\mathrm{SR}-\mu \mathrm{CT}$ & Data visualization & {$[99]$} \\
\hline Advicor & $\begin{array}{l}\text { First and third derivative UV spectropho- } \\
\text { tometry }\end{array}$ & H-point standard addition method & [102] \\
\hline Qingkailing injection & UV spectra & LS-SVM & [103] \\
\hline Propolis & NIRS, HPTLC, FLD & PLS-R, HCA, OPLS-DA & [107] \\
\hline San-Huang tablets & $\begin{array}{l}\text { Spectral quantitative fingerprinting (UV, } \\
\text { FT-IR, CH) }\end{array}$ & SQFM & [116] \\
\hline
\end{tabular}

clinical biological activity cannot be measured, the biological assessment techniques introduced into the system for the quality control of natural herbal medicines can not only identify varieties and quality but also determine pharmacodynamics and even observe toxicity and side effects, further control of biological consistency. 


\section{Bioassay}

Bioassay is based on the efficacy of natural herbal medicines. Quantitative pharmacology and pharmacological analysis are used to characterize the biological effects of natural herbal medicines qualitatively and quantitatively to control or evaluate their internal quality. The techniques mainly comprise the biopotency assay, biological toxicity potency assay, and bioactivity limits assay, etc. [120].

Biopotency refers to the specific biological effects of the test and control substances on a biological system under specific test conditions, and bioavailability methods are used to titrate the intensity of the biological effect of the test substance against that of the reference substance. The biological titer used for determining toxicity is also known as the biological toxicity potency. Assays of biopotency (toxicity) are quantitative methods, and their results are easy to quantify and measure with consistency. Biopotency is mainly applicable to the assessment of natural herbal medicines of which the efficacy is unclear, the efficacy of genuine medicinal materials, the grades of pharmaceutical products and rare natural herbal medicines, trends in activity, and obvious doseeffect relationships within a certain dose range. Biological toxicity potency is mainly applied to the assessment of the quality of toxic natural herbal medicines and provides an objective and accurate technical guarantee for the quality control and rational use of such medicines. The bioactivity limits assay involves semiquantitative or qualitative methods that refer to specific biological effects (such as agglutination, death, or convulsions) on an experimental biological system when the dose of the sample reaches a specific value, and is a semi-quantitative or qualitative method. According to the specific experimental design scheme, methods for the determination of biopotency and biological toxicity can be divided into in vivo and in vitro assays.

Li et al. [121] established a method for the assessment of the quality of Radix Isatidis based on the measurement of its in vitro activity against influenza virus neuraminidase, which indicated that the inhibitory mechanisms of Radix Isatidis and oseltamivir phosphate may be identical. By the method of measuring the potency of the substance, namely, by the comparison of its dose-effect curve with that of the positive control drug oseltamivir, the method of biological assessment of the shape and phases of the curve can be used for the assessment of the quality of Radix Isatidis. Further explore the consistency of biological activity of Radix Isatidis. Han et al. [122] established a biological assessment method for determining the quality of Xuesaitong (XST) capsules that used an in vitro test of biological activity in the form of an antiplatelet aggregation bioassay, and the biological titer was determined by a parallel-line assay. The above provides a basis for the biological evaluation of natural Chinese herbal medicine preparations.

However, there are still few cases in which the assessment of the quality consistency of drugs is carried out using biopotency. This paper intends to quantitatively assess the quality of medicines via biopotency methods with reference to the abovementioned two examples to explore ideas for the development of appropriate biopotency methods in order to determine the consistency of the quality of natural herbal medicines and their preparations.

\section{Bio-response profile}

Biological response profiles refer to a group of characteristic biological data or maps that represent the effects of the sample on a biological system under specific experimental conditions, usually with time-effect or doseeffect dependence.

The most widely used Bio-response profile is the microcalorimetry. Microcalorimetry is a new method for assessing drug quality based on thermodynamics. In one sense, the system of life on earth is a thermodynamic system, and the laws governing living organisms follow the laws of thermodynamics. Both the metabolism of organisms themselves and the interactions between drugs and the body are accompanied by energy conversion and thermal changes. Therefore, according to the abovementioned theories, the bioactivity of drugs can be determined by methods based on biothermodynamics. The changes in energy due to the interactions between different drugs and the body can be measured in real time online and efficiently, and the intrinsic quality of a natural herbal medicine is expressed as a characteristic "fingerprint," namely, its bioactivity fingerprint. By combining certain thermodynamic parameters to establish a mathematical model, the efficacy of a drug can be determined. Wu et al. [123] used microcalorimetry to study the biothermographic fingerprint of the interaction between Qingkailing injection and Staphylococcus aureus. Via similarity analysis, the analysis of biothermodynamic parameters, and comprehensive cluster analysis, a new idea for the biological assessment of the consistency of the quality of Qingkailing injection was proposed. Sha et al. [124] used microcalorimetry to determine the effects of 11 batches of Lianhuaqing capsules (LQCs) on the growth and metabolism of Pseudomonas aeruginosa at different concentrations, which provided a methodological reference for the assessment of the consistency of the quality of other natural herbal medicinal compounds. 


\section{Biological gene expression profile}

With the rapid development of genetic biological information, the identification of organisms via genetic information is a popular research direction among researchers. The biological gene expression profile is a narrow expression of transcriptomics, which is a discipline that studies gene transcription and transcriptional regulation in cells at an overall level. The expression profile can reflect the full effect of the drug on the biological system, so this technology can be used to screen out the mRNA that can characterize the activity of natural herbs and to monitor and evaluate the consistency of biological activity between natural herbal batches. Sun et al. [125] used HepG2 human hepatoma cells as a biodetector and selected six batches of compound Danshen dripping pills. After treatment for $24 \mathrm{~h}$ according to four corresponding criteria, 10 mRNA sequences, which could represent the biological activity of drugs, were screened by a gene expression microarray and quantitative real-time polymerase chain reaction. These sequences corresponded to the MMP1, CYP1A1, EPGN, RUNX2, C8orf4, OLR1, $C L M P, A K R 1 C 1, I L 24$, and APOL6 genes, respectively, which exhibit significant dose-effect dependence. Similarity analysis was carried out according to the differences in the expression levels of the indicator genes for each batch of drugs, and the consistency of the bioactivity of the compound Danshen dripping pills was further assessed.

Each of the above three biometric methods has its advantages. Bioassay is a relatively simple and convenient method, which is mainly used for the in vitro evaluation of natural herbs. The consistency of samples can be obtained by comparing with standard substances according to intuitive phenomena such as color or aggregation state. Biological response profiles can detect the dynamic changes of samples. In comparison with the bioassay, biological response profiles can provide more fingerprint information and indicate the dynamic influence of a drug on an organism. Different from the above two methods, the biological gene expression profile can continuously monitor the differences of samples through the detection of multiple genes, more accurately reflect the differences in the biological information of the samples, and further evaluate the differences in consistency. However, it has higher requirements for the precision and operability of the experiment, so it is suitable for further research and development.

\section{Other biological evaluation techniques}

The research of biological evaluation technology is not only aimed at the study of drug bioequivalence, but more importantly, the quality of drugs is evaluated by the correlation of drug efficacy. The above biological evaluation methods have application examples to support. However, there are still many biological evaluation techniques without quality consistency application examples, which can be qualitatively identified and quantitatively evaluated, and have application prospects for quality consistency evaluation, such as biomarkers, high content analysis, biochips and so on [126-133].

Biomarker is an indicator that can be used to objectively measure and assess a pathological change in a normal biological process or the effect of a drug intervention, and it is an important indicator when an organism receives an intervention. Currently, biomarkers are mainly studied by genomics, proteomics, metabolomics, and other related technologies.

High content analysis is a technique in which cells are used as detection objects, a variety of different fluorescent labels are used, microscopic imaging is used to record images of cells in a multi-well plate, and information in the images is analyzed to detect intracellular material activity. High content analysis technology relies heavily on high-resolution cell imaging systems to enable rapid multivariate analysis of test drugs at the cellular or molecular level.

Biochip immobilizes large number of biomolecules such as nucleic acid fragments, polypeptide molecules, even tissue sections, cells, etc. on a chip (carrier) according to a set manner, and utilizes a specific affinity reaction between biomolecules to realize analysis of the ligand. It features fast, efficient, parallel processing and analytical automation.

The application of biological evaluation methods for quality control is directly related to the biological activity of natural herbal medicines and their preparations, and such methods can be used as a beneficial supplement to physical and chemical indicators and thereby more effectively and accurately determine the consistency and stability of the quality of natural herbal medicines (Fig. 7).

\section{Chemical-biological integration evaluation}

Chemical-biological integration evaluation methods that can reasonably be deduced from the abovementioned chemical and biological assessment methods. Such methods not only use the chemical composition as a detection index but also examine the pharmacodynamics and mechanism of the active ingredients and avoid the shortcomings of quality control models based on "singlecomponent theory." It is difficult to determine the consistency of the quality of natural herbal medicines and their preparations if the assessment of quality is carried out using multiple indices alone without considering the different influences of different components on the overall efficacy of these medicines and preparations. 


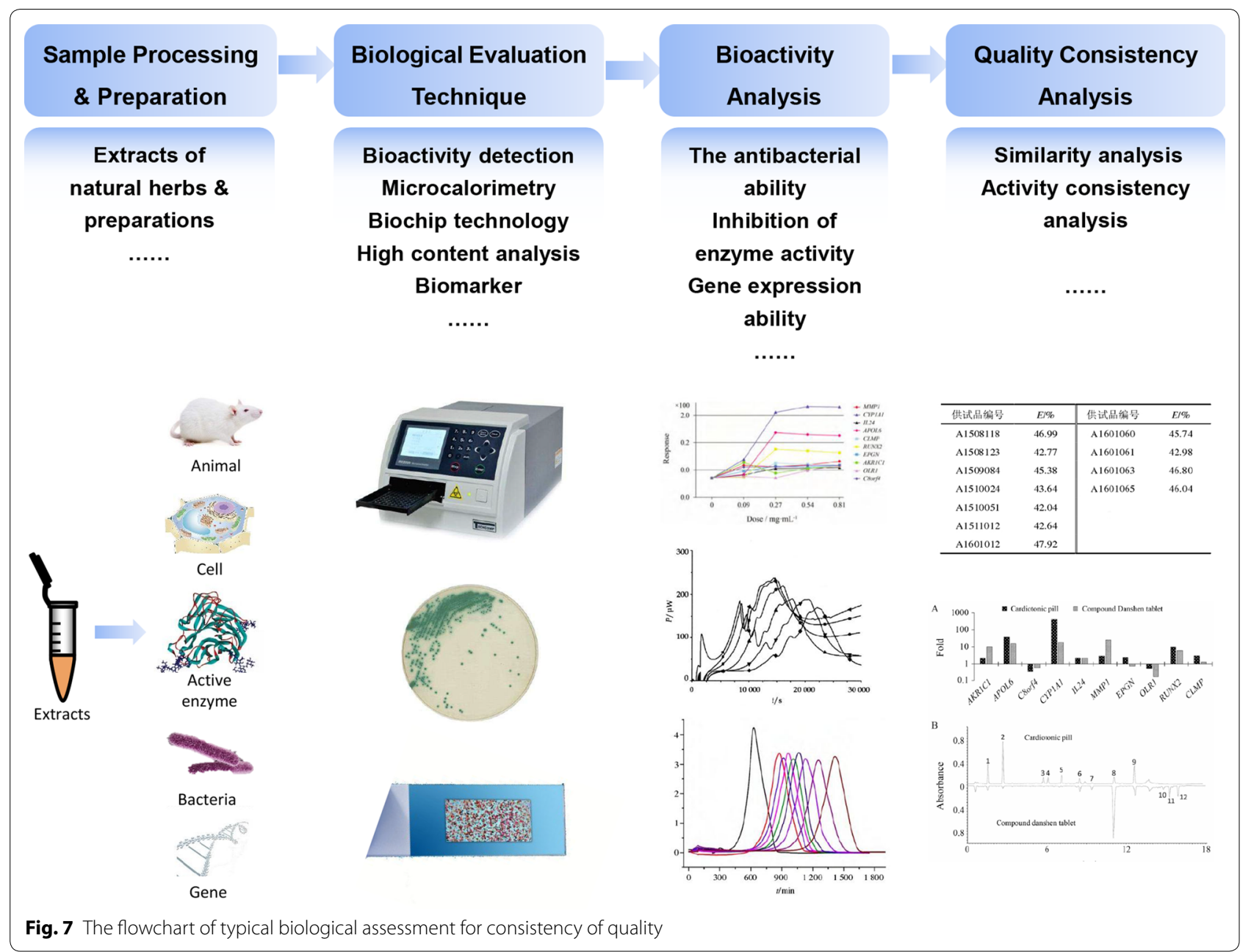

\section{Chemical fingerprint-biological effect profile}

Chemical fingerprinting can be used to characterize the chemical composition of a drug. To better illustrate the consistency of the quality of a drug, a microcalorimetric method can be used to generate a map of biothermal activity. The former determines the consistency of the quality of natural herbal medicines in terms of their chemical compositions, whereas the latter determines the consistency of their drug activity from the efficacy of their bioactive drug constituents and thereby control their quality more comprehensively (Fig. 8). Zhang et al. [134] established a method for the quality control of freeze-dried Shuanghuanglian powder for injection, which was based on mapping its chemical characteristics and biothermal activity. The map of chemical characteristics can effectively illustrate fluctuations in the contents of chemical components of the drug, and the map of biothermal activity can dynamically provide information on the overall biological activity of the drug, thereby assess the quality of freeze-dried Shuanghuanglian powder for injection more effectively. Cheng et al. $[135,136]$ proposed a general method for the quality control of plant medicines based on pharmacologically related chemical and biological fingerprints, namely, plant tissue quality control (PhytomicsQC), using LC/MS chemical characterization and fingerprinting, measurements of differential gene expression in cells for biological response fingerprinting, and in vivo pharmacological validation in animals. Eighteen batches of Astragalus membranaceus and pharmaceutical-grade samples of PHY906 were analyzed to assess the consistency of their quality. Large number of subsequent clinical studies found that PHY906 has the potential to improve an index of cancer treatment, whereas the effect of four batches of commercially produced baicalin decoction was not obvious. However, the abovementioned results cannot be obtained by LC/ MS. Therefore, by employing 18 luciferase reporter cell lines and two enzyme assays based on the mechanism of PHY906, a mechanism-based quality control platform 


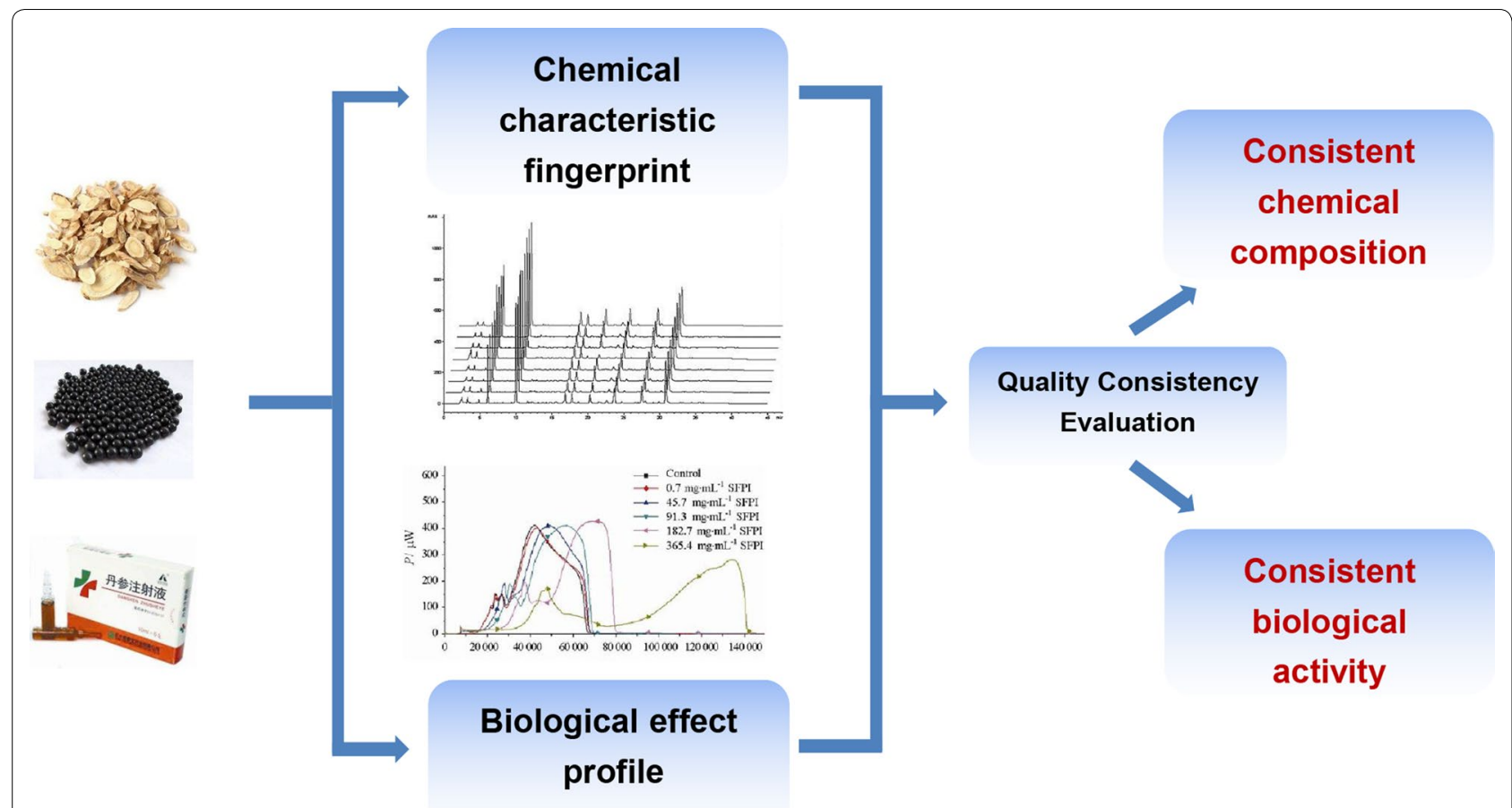

Fig. 8 The flowchart of typical joint chemical-biological assessment for consistency of quality

was established to distinguish between PHY906 and commercial Scutellaria extract.

Recently, researchers have proposed a new average linear quantitative fingerprinting method, combined with liquid phase analysis of antioxidant activity, successfully applied to the quality consistency evaluation of two herbal preparations. The relationship between the efficacy relationship of fingerprints and antioxidant activity was studied by orthogonal projection to latent structures method, which provided important pharmacodynamic information for quality control of traditional Chinese medicine $[137,138]$.

\section{Effective equivalence}

Effective equivalent is a new concept of quality consistency evaluation of natural herbal medicines based on the total amount of biological effects exerted by effective substances. The effector equivalent is centered on the "effectconstituent index" [139], which is based on the common weighting of chemical composition analysis and biological effect detection (Fig. 9). The effect-constituent index calculates the sum of the effects of all pharmacodynamics or active ingredients based on the pharmacological effect or the biological activity intensity of the active ingredient as the weight of the chemical content, and usually reflects the quality information related to a specific efficacy of the natural herbal medicines. The establishment of the effective equivalence enables the quality standard of natural herbal medicines to achieve a practical correlation with the curative effect of the drug in the current controllable condition, and provides a reference for clinical application. The effective equivalence reflects the difference in quality between different medicinal materials. The high effect equivalent reflects the good quality of the medicinal material and the low effect equivalent, which reflects the poor quality of the medicinal material. This leads to the concept of "consistency of efficacyequivalent," which refers to the equivalence of the total biological effects of the active ingredients [22]. Its main function is to ensure that the pharmacodynamic effects of drugs produced in each batch are consistent by model biological calculations. In the course of clinical drug use, only the consistency of efficacy-equivalent is guaranteed, that is, the total amount of biological effects exerted by the effective substances is equal, so as to satisfy the quality, stability and consistency of the quality of traditional Chinese medicines to the greatest extent, and to ensure the safety and effectiveness of clinical drugs. Dong et al. [140] used the effective equivalence model to study the consistency of the dispensing of 18 samples of Rhizoma Coptidis with six different specifications by constructing an effect-constituent index of Rhizoma Coptidis and using PLS-DA, so as to further ensure the stability and consistency of the dispensing of natural herbal medicines 


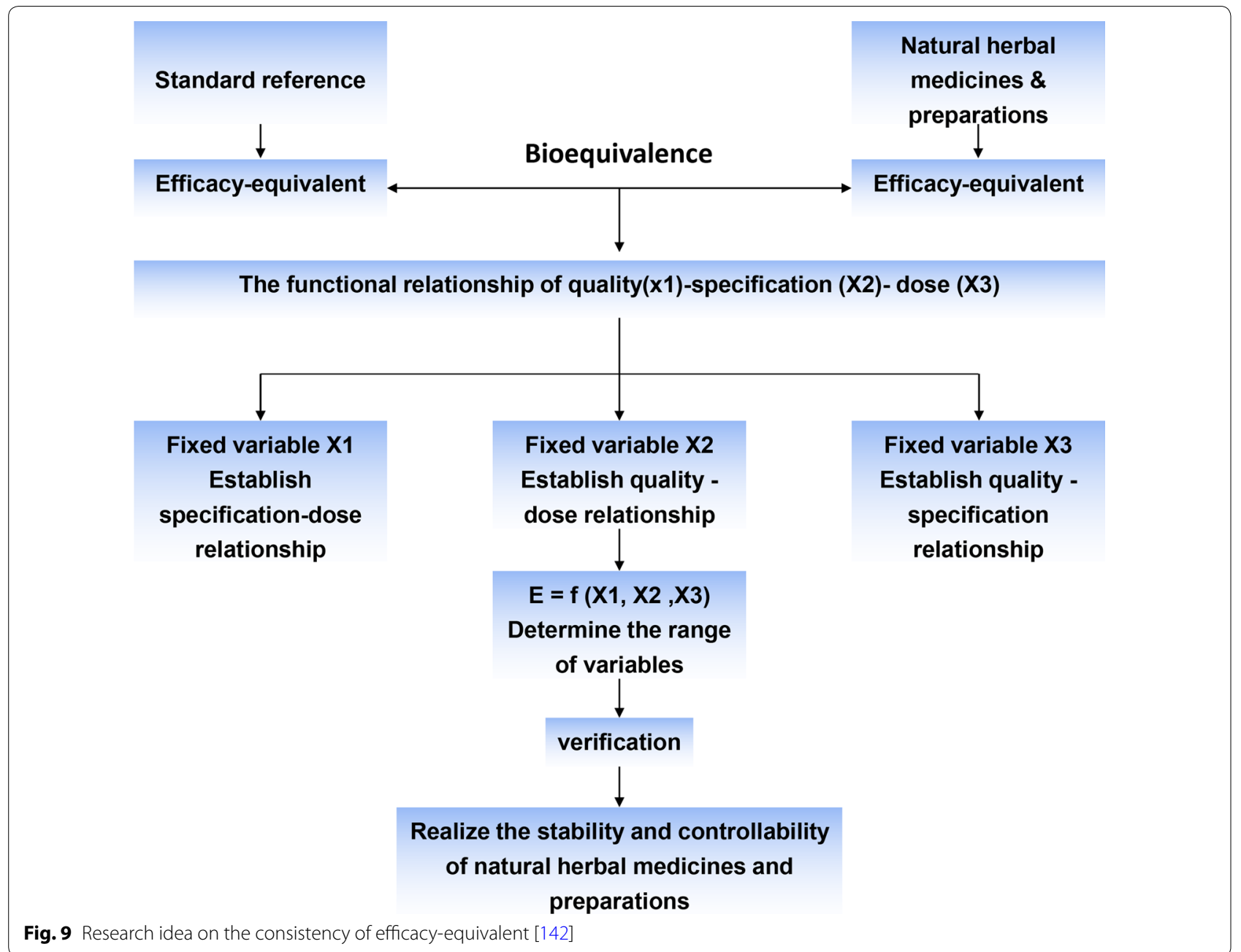

in terms of their clinical efficacy. Similarly, Zhang et al. [141] took Rhizoma Coptidis as an example and proposed a comprehensive quality evaluation strategy for the consistency of traditional Chinese medicine formula granules with traditional decoctions.

\section{Metabolomics}

The quality evaluation of natural herbal medicines based on metabolomics can more clearly clarify the complex components of natural herbal medicines and its pharmacodynamics and mechanism. Based on ${ }^{1} \mathrm{H}-\mathrm{NMR}$ metabolomics technology, the information of active ingredients of natural herbal medicines can be extracted and detected comprehensively, and the quality evaluation method that accords with the overall characteristics of the medicines can be established to ensure the consistency of the quality of the medicines [143-145]. Ma et al. [146] selected toad venom with anti-tumor activity as a model and developed a metabolite-based screening and quality consistency control (MSQCC) pipeline as a potential solution to this long-term problem. The study first demonstrated the efficacy of the metabolomics and biological profile correlation screening of 180 fractions prepared from natural heterogeneous venom samples to identify a series of bufadienolides as quality control markers for cancer cell inhibition. Finally, we developed a markerbased blending program (Markers-NMBT) to standardize the heterogeneity of natural medicinal substances (NMS). It creates blends that transform unqualified venoms with highly varying contents of bufadienolides, into qualified products that meet reference standards. Therefore, this work provides a strategie for rapid, large-scale discovery, quantification, and application of quality control markers to ensure consistency between batches and may be a key technology in the development of modern NMS formulations. 
Chemical fingerprint-biological effect profile combines the chemical fingerprint and biological response spectrum to reflect the consistent changes in the chemical composition and biological efficacy of the drug. Its operation and application are relatively simple, and it can also observe the dynamic change process of the sample. Effective equivalence is to construct a mathematical model, express the chemical composition information and biological efficacy information with metrology, intuitively reflect the effective equivalent of the sample, and reflect the consistency of the drug. However, its application is still in its infancy, and there are not enough application examples. It needs to be further developed in the future. Metabolomics is currently a widely used and mature technology, but metabolomics has a large amount of information and needs to be compared with databases, so there are certain deficiencies in data visualization (Table 4).

\section{Conclusion}

The control of the quality consistency of natural herbal medicines has always been one of the key points and difficulties in their internationalization and modernization. With the modernization of natural herbal medicines, methods for assessing the consistency of the quality of natural herbal medicines have included advanced analytical techniques in the fields of chemical, physical, and biological assessment. Among the many evaluation methods mentioned in this article, they are applicable to the quality consistency evaluation of natural medicines. For scientific research, many scholars still use chromatography and further combine some biological activity evaluation for small-scale research. In industrial production, due to the concentration of research objects, more and more manufacturers have begun to use spectrometry to quickly and real-time check the consistency of pharmaceutical preparations. However, the clinical application of natural herbs has gradually deepened, and it is not appropriate to consider the consistency of the chemical composition alone, so the combination of chemical composition and biological activity for evaluation will be the future development trend.

For single herbals, the quality of a single herbs can be evaluated in both chemical and biological aspects; while multi-component herbal preparations should not only consider the effects of various herbal ingredients, but also consider how to control production online from the perspective of the formulation process to meet the consistency requirements of the formulation. In addition, it is necessary to consider the effect of the formulation dosage form on consistency, such as dissolution, degree of disintegration, and the like.

Modern methods for determining the consistency of the quality of drugs are more closely associated with their clinical mechanisms and have the advantages of rapidity, comprehensiveness, non-destructiveness, and efficiency. The mechanisms of action of drugs have been shown to be strongly correlated with their clinical effects. In particular, in the case of the natural medicinal system represented by natural herbal medicine, which involves complex components, we must not only monitor the components with high activity and high contents, that is, the iconic components, but also control the overall compositional profile and thus achieve the goal of "not only seeing the towering trees, but also the outline of the forest."

This article has reviewed methods used for the assessment and control of the quality consistency in the complex system of natural medicine. We hope it can provide methodological references and guidance for the quality consistency evaluation, explore scientific evaluation methods of quality consistency, and lay a foundation for the industrialization and clinical application of natural herbal medicines, which will be benefit for the modernization and internationalization of natural herbal medicines. 
Table 4 Quality consistency evaluation with biological evaluation and chemical-biological integration evaluation technology

\begin{tabular}{|c|c|c|c|}
\hline Sample & Detection method & Analytical method & References \\
\hline Scutellariae Radix & $\begin{array}{l}\text { HPLC-PDA/QTOF-MS, antioxidant and anti- } \\
\text { inflammatory bioactivities assays }\end{array}$ & $\begin{array}{l}\text { Multivariate statistical analysis-based bridging, } \\
\text { SA, HCA }\end{array}$ & {$[117]$} \\
\hline Radix Isatidis & Neuraminidase activity assay & Parallel lines of qualitative effect & {$[121]$} \\
\hline XST capsules & Antiplatelet aggregation & Parallel line assay & [122] \\
\hline Xiaojin Pills & Antiplatelet aggregation & Simplified probit principle & [149] \\
\hline Qingkailing injection & Bioactivity fingerprints & SA, One-way anova, CA & [123] \\
\hline Lianhua Qingwen capsules & $\begin{array}{l}\text { Microcalorimetry, growth metabolic thermo- } \\
\text { gram }\end{array}$ & Regression analysis & [124] \\
\hline Cardiotonic Pills & Gene chip, qrt-PCR, UPLC fingerprint & SA & {$[125]$} \\
\hline $\begin{array}{l}\text { Shuanghuanglian freeze-dried } \\
\text { powder for injection }\end{array}$ & HPLC-ELSD fingerprints, Microcalorimetry & SA & [134] \\
\hline Huangqin Tang, PHY906 & $\begin{array}{l}\text { LC/MS fingerprinting, bioresponse fingerprint- } \\
\text { ing, in vivo validation, } 18 \times \text { Luciferase report } \\
\text { cell lines }\end{array}$ & Phytomics Similarity Index (PSI) & {$[135,136]$} \\
\hline YIQING tablets & HPLC-DAD fingerprint, HPLC-DPPH assay & $\begin{array}{l}\text { PCA, average linear quantitative fingerprint, } \\
\text { multiwavelength total fusion profiling }\end{array}$ & [137] \\
\hline Powdered Poppy capsules & HPLC fingerprint, Antioxidant Activities & $\begin{array}{l}\text { Averagely linear-quantified fingerprint method, } \\
\text { OPLS }\end{array}$ & [138] \\
\hline Coptidis Rhizoma & HPLC fingerprint & Effective constituent equivalence, PLS-DA & [140] \\
\hline Coptidis Rhizoma & HPLC, antibacterial zone & $P C A, I C_{50}$ & [141] \\
\hline Huangqi injection solution & ${ }^{1} \mathrm{H}$ NMR Fingerprint & SA, relative content determination & [145] \\
\hline Bufo bufo gargarizans Cantor & $\begin{array}{l}\text { LC-MS/MS, Cytotoxicity assay in vitro, metabo- } \\
\text { lomic }\end{array}$ & Markers-NMBT & [146] \\
\hline Salvia miltiorrhiza Bunge & $\begin{array}{l}\text { Micellar electrokinetic capillary chromatography } \\
\text { fingerprint, antioxidant activity }\end{array}$ & SQFM, PCA & {$[147]$} \\
\hline Tianma Toutong tablets & $\begin{array}{l}\text { HPLC five-wavelength fingerprints, antioxidant } \\
\text { activity }\end{array}$ & SQFM, PCA, PLS model & [148] \\
\hline Lianqiao Baidu Pills & $\begin{array}{l}\text { HPLC five-wavelength fingerprints, antioxidant } \\
\text { activity }\end{array}$ & $\begin{array}{l}\text { Limited-ratio quantified fingerprint method, } \\
\text { PCA, PLS model }\end{array}$ & {$[150]$} \\
\hline Sanhuang tablets & $\begin{array}{l}\text { Capillary electrophoresis fingerprints, antioxi- } \\
\text { dant activity }\end{array}$ & PLS model & [151] \\
\hline Yinqiaojiedu tablets & $\begin{array}{l}\text { Capillary electrophoresis fingerprints, antioxi- } \\
\text { dant activity }\end{array}$ & PCA, PLS model & [152] \\
\hline Sophora flavescens & $\begin{array}{l}\text { Capillary electrophoresis fingerprints, antioxi- } \\
\text { dant activity }\end{array}$ & Linear quantitative profiling method, PLS model & [153] \\
\hline Weibizhi tablets & $\begin{array}{l}\text { Micellar electrokinetic chromatography finger- } \\
\text { printing, antioxidant activity }\end{array}$ & $\begin{array}{l}\text { Simple quantified ratio fingerprint method, PLS } \\
\text { model }\end{array}$ & [154] \\
\hline Fufang Danshen Pills & $\begin{array}{l}\text { Micellar electrokinetic chromatography finger- } \\
\text { print, Antioxidant activity }\end{array}$ & SQFM, PLS model & {$[155]$} \\
\hline Ixeris sonchifolia & $\begin{array}{l}\text { Microemulsion electrokinetic chromatography } \\
\text { fingerprints, antioxidant activity }\end{array}$ & PCA, OPLS & {$[156]$} \\
\hline Ixeris sonchifolia & HPLC fingerprint, antioxidant activity & SQFM, SVM, PCA, PLS, OPLS & [157] \\
\hline Sophora flower-bud, Sophora flower & $\begin{array}{l}\text { HPLC-Q-TOF MS, antioxidant and hyaluronidase } \\
\text { inhibitory activities }\end{array}$ & PLSR, BP-ANN, PCA & [158] \\
\hline Matricaria chamomilla L. & HPLC fingerprint, antioxidant activity & PCA, HCA & [159] \\
\hline Compound Danshen tablets & $\begin{array}{l}\text { HPLC multiwavelength fusion fingerprints, } \\
\text { antioxidant activity }\end{array}$ & SQFM, SA, & [160] \\
\hline Lianqiao Baidu Pills & $\begin{array}{l}\text { Micellar electrokinetic capillary chromatography } \\
\text { fingerprint, antioxidant activity }\end{array}$ & $\begin{array}{l}\text { Limited-ratio quantified fingerprint method, } \\
\text { PCA, HCA, PLS model }\end{array}$ & [161] \\
\hline Isatidis Folium & HPLC fingerprint, antioxidant activity & $\begin{array}{l}\text { Equal weight quantified ratio fingerprint } \\
\text { method, PLSR }\end{array}$ & [162] \\
\hline Compound Liquorice tablets & $\begin{array}{l}\text { HPLC multi-wavelength fusion fingerprint, } \\
\text { antioxidant activity }\end{array}$ & $\begin{array}{l}\text { Averagely linear quantified fingerprint method, } \\
\text { HCA, PCA, PLS model }\end{array}$ & [163] \\
\hline Zhenju Jiangya tablets & $\begin{array}{l}\text { HPLC multi-wavelength fusion fingerprint, } \\
\text { antioxidant activity }\end{array}$ & SQFM, PCA, PLS model & [164] \\
\hline
\end{tabular}




\begin{abstract}
Abbreviations
LC: Liquid chromatography; GC: Gas chromatography; MS: Mass spectrometry: DART-MS: Direct analysis in real time mass spectrometry; QAMS: Quantitative analysis of multiple components by a single marker; NIRS: Near-infrared spectroscopy; LIBS: Laser-induced breakdown spectroscopy; SR- $\mu$ CT: Synchrotron radiation X-ray computed microtomography; SQFM: Systematic quantified fingerprint method; SA: Similarity analysis; PCA: Principle component analysis; HCA: Hierarchical clustering analysis; PLS-DA: Partial least squares discriminant analysis; PLSR: Partial least squares regression; MSC: Multiplicative scatter correction; ANN: Artificial neural network; LDA: Linear discriminant analysis; FLD: Fluorescence detection.
\end{abstract}

\section{Acknowledgements}

\section{Not applicable.}

\section{Authors' contributions}

$\mathrm{X}-\mathrm{CW}, \mathrm{D}-\mathrm{KZ}$, and $\mathrm{LH}$ conceived and designed the paper; BC, C-HL, H-ZH, and $X-R X$ gave some advice for improving the paper; R-CX, PT, MY, and YZ gave some advice for improving the picture; $\mathrm{X}-\mathrm{CW}$, wrote the paper. All authors read and approved the final manuscript.

\section{Funding}

The authors would like to acknowledge the financial support from National Natural Science Foundation of China (81773918), Sichuan Outstanding Young Science and Technology Talents Project (2019JDJQ0007), and Sichuan Science and Technology Program (Grant number 2019YJ0640).

\section{Availability of data and materials}

Not applicable.

\section{Ethics approval and consent to participate}

Not applicable.

\section{Consent for publication}

The manuscript is approved by all authors for publication.

\section{Competing interests}

The authors declare no competing financial interests.

\section{Author details}

1 School of Pharmacy, State Key Laboratory of Characteristic Chinese Drug Resources in Southwest China, Chengdu University of Traditional Chinese Medicine, No. 1066 Avenue. Liutai, Chengdu 611137, China. ${ }^{2}$ Sichuan Academy of Traditional Chinese Medicine, State Key Laboratory of Quality Evaluation of Traditional Chinese Medicine, Chengdu 610041, China. 3 Jiangxi University of Traditional Chinese Medicine, Nanchang 330004, China.

${ }^{4}$ Chengdu Food and Drug Control, Chengdu 610000, China.

Received: 17 March 2020 Accepted: 20 May 2020

Published online: 01 June 2020

\section{References}

1. Zhang DK, Han X, Li RY, Niu M, Dong Q, Yang M, Wang JB, Xiao XH. Investigation of the chemical markers for experiential quality evaluation of crude aconite by UHPLC-Q-TOF-MS. J Sep Sci. 2016;39:4281-9.

2. Zhang DK, Han X, Tan P, Li RY, Niu M, Zhang CE, Wang JB, Yang M, Xiao $\mathrm{XH}$. Establishment of one-step approach to detoxification of hypertoxic aconite based on the evaluation of alkaloids contents and quality. Chin J Nat Med. 2017;15:49-61.

3. van Beek TA, Montoro P. Chemical analysis and quality control of Ginkgo biloba leaves, extracts, and phytopharmaceuticals. J Chromatogr A. 2009;1216:2002-32.

4. Xu XR, Zhang T, Li P, Xu Q, Feng B, Tan P, Cao JH, Xu RC, Zhang DK, Han L. Overview and prospects of traditional Chinese medicine blending technology oriented by quality consistency. Chin J Chin Mater Med. 2019:44:4786-92.

5. U.S. Department of Health and Human Services, Food and Drug Administration, Center for Drug Evaluation and Research. Guidance for industry botanical drug products. 2004. https://www.fda.gov/downl oads/aboutfda/centersoffices/centerfordrugevaluationandresearch/ ucm106136.pdf.

6. U.S. Department of Health and Human Services, Food and Drug Administration, Center for Drug Evaluation and Research. Botanical drug development guidance for industry. 2016. https://www.fda.gov/downl oads/drugs/guidancecomplianceregulatoryinformation/guidances/ ucm458484.pdf.

7. Suarez-Sharp S, Delvadia PR, Dorantes A, Duan J, Externbrink A, Gao Z, Ghosh T, Miksinski SP, Seo P. Regulatory perspectives on strength dependent dissolution profiles and biowaiver approaches for immediate release (IR) oral tablets in new drug applications. AAPS J. 2016;18:578-88.

8. Anand O, Yu LX, Conne DP, Davit BM. Dissolution testing for generic drugs: an FDA perspective. AAPS J. 2011;13:328-35.

9. Zhang DK, Li RS, Han X, Li CY, Zhao ZH, Zhang HZ, Yang M, Wang JB, Xiao XH. Toxic constituents index: a toxicity-calibrated quantitative evaluation approach for the precise toxicity prediction of the hypertoxic phytomedicine-aconite. Front Pharmacol. 2016;17:164.

10. Xiao XH. Development of traditional Chinese medicine: new Era and new strategy. Chin J Chin Mater Med. 2019;18:3837-41.

11. Li HB, Wu SH, Niu M, Wang JB, Xiao XH. History and development of biological assay for quality of Chinese materia medica. Chin Tradit Herb Drugs. 2017:48:2809-16.

12. Zhang XR, Wang JB, Xiao XH, Liu TS, Chu XH, Zhou CP, Jin C. Antimicrobial activity and chemical differences between the two chemotypes of rhubarbs. Acta Pharm Sin. 2010;45:1144-8.

13. Zou CC, Yan HY. Research progress on chromatographic fingerprint similarity evaluation method for traditional Chinese medicine in the past 30 years (1988-2017) and its prospect. China J Chin Mater Med. 2018:43:1969-77.

14. China Pharmacopoeia Committee. Pharmacopoeia of the People's Republic of China. 2015th ed. Beijing: China Medical Science and Technology Press; 2015.

15. Gao HM, Song ZH, Wang ZM, Qian ZZ, Zhang QW. Overview on quantitative analysis of multi-components by single-marker. China J Chin Mater Med. 2012;37:405-16.

16. Ufret C, Morris K. Modeling of power blending using on-line nearinfrared measurements. Drug Dev Ind Pharm. 2001;27:719-29.

17. Okumura T, Otsuka M. Evaluation of the microcrystallinity of a drug substance, indomethacin, in a pharmaceutical model tablet by chemometric FT-Raman spectroscopy. Pharm Res. 2005;22:1350-7.

18. Pouzar M, Kratochvíl T, Capek L, Smoláková L, Cernohorský T, Krejcová A, Hromádko L. Quantitative LIBS analysis of vanadium in samples of hexagonal mesoporous silica catalysts. Talanta. 2011;83:1659-64.

19. Huang HZ, Zhao SY, Ke XM, Lin JZ, Huang SS, Xu RC, Ma HY, Zhang Y, Han L, Zhang DK. Study on the stability control strategy of Triphala solution based on the balance of physical stability and chemical stabilities. J Pharm Biomed Anal. 2018;158:247-56.

20. Xiong $Y$, Xiao XH, Yan D, Wang JB, Yan YH. An integrated method for quality control of Chinese materia medica based on effect-constituent index. Chin Tradit Herb Drugs. 2014;45:1-7.

21. Zhang $T$, Huang $H Z$, Xu RC, Wang JB, Yang $M$, Cao JH, Zhang Y, Zhang DK, Han L. An anti-influenza virus activity-calibrated chemical standardization approach for quality evaluation of indigo naturalis. Anal Methods. 2019;11:4719-26.

22. Zhang $\mathrm{HZ}$, Xiao $\mathrm{XH}$, Wang JB, Wang J. Consistency of efficacyequivalent: key essential point of quality control for Chinese materia medica. Chin Tradit Herb Drugs. 2015;46:1571-5.

23. Han L, Zhang F, Zhang DK, Tang YX, Yang YG, Yang M. Determination methods of content uniformity in preparations of Chinese materia medica. Chin Tradit Herb Drugs. 2014;45:2125-31.

24. Zeng S, Chen T, Wang L, Qu H. Monitoring batch-to-batch reproducibility using direct analysis in real time mass spectrometry and multivariate analysis: a case study on precipitation. J Pharm Biomed Anal. 2013;76:87-95.

25. Buchberger AR, DeLaney K, Johnson J, Li L. Mass spectrometry imaging: a review of emerging advancements and future insights. Anal Chem. 2018;90:240-65.

26. Madathilethu J, Roberts M, Peak M, Blair J, Prescott R, Ford JL. Content uniformity of quartered hydrocortisone tablets in comparison 
with mini-tablets for paediatric dosing. BMJ Paediatr Open. 2018;2:e000198.

27. Oliva A, Fariña JB, Llabrés M. Development and validation of an UPLC method for determination of content uniformity in low-dose solid drugs products using the design space approach. Talanta. 2013;115:490-9.

28. Tang JF, Zhang SQ, Wang XY, Li WX, He YN, Cao ZX, Zhang DK. Quality consistency evaluation of Fuzi formula granules using determination of multi-component contents by HPLC-MS/MS method. China J Chin Mater Med. 2018:43:1871-9.

29. Arceusz A, Wesolowski M. Quality consistency evaluation of Melissa officinalis L. commercial herbs by HPLC fingerprint and quantitation of selected phenolic acids. J Pharm Biomed Anal. 2013;83:215-20.

30. Xiong H, Yu LX, Qu H. Batch-to-batch quality consistency evaluation of botanical drug products using multivariate statistical analysis of the chromatographic fingerprint. AAPS PharmSciTech. 2013;14:802-10.

31. Lu PF, Chen Y, Tan ML, Wu Y. Chemical profiling by LC-MS/MS and HPLC fingerprint combined with chemometrics and simultaneous determination of 16 characteristic ingredients for the quality consistency evaluation of Shaoyao-Gancao Decoction. Biomed Chromatogr. 2019;33:e4401.

32. Sun GX, Sun WY, Zhang J, Hou ZF, Yang FL, Li XL, Hu YL, Wang SD, Wu S. TCM quality evaluation consistency system-the analysis for control mode of standard preparation based on quantitative fingerprints. Cent South Pharm. 2018;16:1-13.

33. Wang $\mathrm{P}$, Nie L, Zang H. A useful strategy to evaluate the quality consistency of traditional Chinese medicines based on liquid chromatography and chemometrics. J Anal Methods Chem. 2015;2015:589654.

34. Zhang J, Sun G. Assessment of quality consistency in traditional Chinese medicine using multi-wavelength fusion profiling by integrated quantitative fingerprint method: Niuhuang Jiedu pill as an example. J Sep Sci. 2019;42:509-21.

35. Liu Y, Liu Z, Sun G, Wang Y, Ling J, Gao J, Huang J. Monitoring and evaluating the quality consistency of compound bismuth aluminate tablets by a simple quantified ratio fingerprint method combined with simultaneous determination of five compounds and correlated with antioxidant activities. PLoS ONE. 2015;10:e0118223.

36. Zhang YJ, Wang C, Yang FL, Yang Z, Wang FR, Sun GX. UHPLC-ESI-QTOF-MS/MS analysis, antioxidant activity combined fingerprints for quality consistency evaluation of compound liquorice tablets. RSC Adv. 2018;8:27661-73.

37. Yan B, Yang L, Ma D, Sun G. Comprehensively evaluating the quality consistency of Liuwei Dihuang pill by five-wavelength overall fused HPLC fingerprints combined with simultaneous determination and antioxidant activity. J Chromatogr Sci. 2017;55:1026-36.

38. Yan B, Sun G. Monitoring quality consistency of Liuwei Dihuang Pill by integrating the ultraviolet spectroscopic fingerprint, a multi-wavelength fusion fingerprint method, and antioxidant activities. J Sep Sci. 2018:41:1182-91.

39. Zhu C, Li X, Zhang B, Lin Z. Quantitative analysis of multi-components by single marker - a rational method for the internal quality of Chinese herbal medicine. Integr Med Res. 2017;6:1-11.

40. Li F, Wu H, Sun LL, Wu H, Wang R, Li SP, Wang WY, Dai L, Zhang ZR, Fu J, et al. Quantitative analysis of multi-components by single marker and fingerprint analysis of Achyranthes bidentata Blume. J Chromatogr Sci. 2018;56:595-603.

41. Yan H, Sun GX, Chi HX, Zhang J, Sun WY, Hou ZF, Li XL, Pu DJ, Chen ZH. Quality consistency evaluation of Fufanggancao tablets based on the control mode of standard preparation and quantitative fingerprint. Chin J Chromatogr. 2019;37:1200-8.

42. Sun HJ, Du YB, Yu ZF, Dong ZJ. Determination of the mass consistency of extract of Ginkgo biloba leaves injection of different manufacturers by UPLC-MS/MS method. Chin J Clin Pharmacol. 2019;35:2407-11.

43. Xu N, Sun R, Cui HY, Huang X, Li XY, Wang L, Shi HY. Optimization of extraction technology of Banxia Baizhu Tianma Decoction by chemometrics combined with information entropy weighting. Chin Tradit Herb Drugs. 2020;51:995-1002.

44. Wang H, Chen M, Li J, Chen N, Chang Y, Dou Z, Zhang Y, Zhuang P, Yang Z. Quality consistency evaluation of Kudiezi injection based on multivariate statistical analysis of the multidimensional chromatographic fingerprint. J Pharm Biomed Anal. 2020;177:112868.
45. Cao XC, Zhang XY, Xu JD, Shen H, Zhou SS, Zhu H, Kong M, Zhang W, Zhou GR, He Y, et al. Quality consistency evaluation on four origins of Cicadae Periostracum by ultra-performance liquid chromatography coupled with quadrupole/time-of-flight mass spectrometry analysis. J Pharm Biomed Anal. 2020;179:112974.

46. Hou YZ, Li B, Xiao HM, Chen JL, Li Z, Li WL. Determination of saponins in Xuesaitong Drop Pills and study on batch consistency evaluation techniques. Chin Tradit Herb Drugs. 2019;11:2552-9.

47. Sun $X$, Tang $X$, Yang Q. An effective quantitative fingerprint method for evaluating the quality consistency of Desmodium styracifolium. Pharmazie. 2018;73:579-84.

48. Xiong X, Pan Y, Zhang T, Yang M, Tan QC, Xu RC, Zhang DK, Han L. Consistency evaluation of commercially Xiaojin Pills using determination of multicomponent contents by HPLC-MS/MS method coupled with chemometrics. Chin Tradit Herb Drugs. 2017;1 1:2189-96.

49. Wu DT, Deng Y, Chen LX, Zhao J, Bzhelyansky A, Li SP. Evaluation on quality consistency of Ganoderma lucidum dietary supplements collected in the United States. Sci Rep. 2017;7:7792.

50. Ma DD, Gong DD, Sun GX, Yang FL. Quality evaluation of Yinqiaojiedu tablets by three wavelength fusion fingerprint combined with six components quantitative determination and principal component analysis. Chin J Chromatogr. 2017;7:741-7.

51. Wang $L$, Tian $X$, Wei W, Chen G, Wu Z. Fingerprint analysis and quality consistency evaluation of flavonoid compounds for fermented Guava leaf by combining high-performance liquid chromatography timeof-flight electrospray ionization mass spectrometry and chemometric methods. J Sep Sci. 2016;39:3906-16.

52. Viapiana A, Wesolowski M. HPLC fingerprint combined with quantitation of phenolic compounds and chemometrics as an efficient strategy for quality consistency evaluation of Sambucus nigra Berries. Nat Prod Commun. 2016;11:1449-54.

53. Sharma DK, Kim SG, Lamichhane R, Lee KH, Poudel A, Jung HJ. Development of UPLC fingerprint with multi-component quantitative analysis for quality consistency evaluation of herbal medicine "Hyangsapyeongwisan". J Chromatogr Sci. 2016;54:536-46.

54. Xie B, Gong T, Tang M, Mi D, Zhang X, Liu J, Zhang Z. An approach based on HPLC-fingerprint and chemometrics to quality consistency evaluation of Liuwei Dihuang Pills produced by different manufacturers. J Pharm Biomed Anal. 2008:48:1261-6.

55. Xie Y, Jiang ZH, Zhou H, Cai X, Wong YF, Liu ZQ, Bian ZX, Xu HX, Liu L. Combinative method using HPLC quantitative and qualitative analyses for quality consistency assessment of a herbal medicinal preparation. J Pharm Biomed Anal. 2007;43:204-12.

56. Li Y, Wu T, Zhu J, Wan L, Yu Q, Li X, Cheng Z, Guo C. Combinative method using HPLC fingerprint and quantitative analyses for quality consistency evaluation of an herbal medicinal preparation produced by different manufacturers. J Pharm Biomed Anal. 2010;52:597-602.

57. De Bleye C, Chavez PF, Mantanus J, Marini R, Hubert P, Rozet E, Ziemons E. Critical review of near-infrared spectroscopic methods validations in pharmaceutical applications. J Pharm Biomed Anal. 2012;69:125-32.

58. Mantanus J, Rozet E, Van Butsele K, De Bleye C, Ceccato A, Evrard B, Hubert P, Ziémons E. Near infrared and Raman spectroscopy as process analytical technology tools for the manufacturing of silicone-based drug reservoirs. Anal Chim Acta. 2011;699:96-106.

59. Yhee JY, Kim SA, Koo H, Son S, Ryu JH, Youn IC, Choi K, Kwon IC, Kim K. Optical imaging of cancer-related proteases using near-infrared fluorescence matrix metalloproteinase-sensitive and cathepsin B-sensitive probes. Theranostics. 2012;2:179-89.

60. Mazin BA, Bumble B, Meeker SR, O'Brien K, McHugh S, Langman E. A superconducting focal plane array for ultraviolet, optical, and nearinfrared astrophysics. Opt Express. 2012;20:1503-11.

61. Park HS, Lee JE, Cho MY, Noh YW, Sung MH, Poo H, Hong KS, Lim YT. pHstimuli-responsive near-infrared optical imaging nanoprobe based on poly(Y-glutamic acid)/poly( $\beta$-amino ester) nanoparticles. Nanotechnology. 2011;22:465603.

62. Williams $\mathrm{PC}$, Norris KH. Near infrared technology in agriculture and food industries. St. Paul: American Association of Cereal Chemists Press; 1987

63. Popo M, Romero-Torres S, Conde C, Romañach RJ. Blend uniformity analysis using stream sampling and near infrared spectroscopy. AAPS PharmSciTech. 2002;3:61-71. 
64. Durand A, Devos O, Ruckebusch C, Huvenne JP. Genetic algorithm optimisation combined with partial least squares regression and mutual information variable selection procedures in near-infrared quantitative analysis of cotton-viscose textiles. Anal Chim Acta. 2007;595:72-9.

65. Zhang C, Su J. Application of near infrared spectroscopy to the analysis and fast quality assessment of traditional Chinese medicinal products. Acta Pharm Sin B. 2014:4:182-92.

66. Shi CX, Yang YW, Guo ZX, Zhu GG. Quantitative analysis on Radix Salviae miltiorrhizae by NIR. J Chin Med Mater. 2006;29:897-9.

67. Yang Y, Wang L, Liu XS, Wu YJ, Bi YA, Xiao W, Chen Y. Application of near infrared spectroscopy combined with multivariate statistical process control for in-line monitoring of extraction of Lonicerae Japonicae Flos. Chin Tradit Herb Drugs. 2017:48:3497-504.

68. Qi SY, Yao SC, Yin LH, Hu CQ. A strategy to assess quality consistency of drug products. Front Chem. 2019;7:171.

69. Ma L, Li Y, Lei L, Zeng J, Zhang J, Qiao Y, Wu Z. Real-time process quality control of ramulus cinnamomi by critical quality attribute using microscale thermophoresis and on-line NIR. Spectrochim Acta A Mol Biomol Spectrosc. 2019;224:117463.

70. Gowena AA, O'Donnell CP, Cullen PJ, Bell SE. Recent applications of chemical imaging to pharmaceutical process monitoring and quality control. Eur J Pharm Biopharm. 2008;6:10-22.

71. Zhou L, Xu M, Wu Z, Shi X, Qiao Y. PAT: from western solid dosage forms to Chinese materia medica preparations using NIR-Cl. Drug Test Anal. 2016:8:71-85

72. Ma L, Zhou L, Xu M, Huang X, Zhang Q, Dai S, Qiao Y, Wu Z. Investigation of the distributional homogeneity on chlorpheniramine maleate tablets using NIR-Cl. Spectrochim Acta A Mol Biomol Spectrosc. 2018;204:783-90.

73. Cruz J, Bautista M, Amigo JM, Blanco M. Nir-chemical imaging study of acetylsalicylic acid in commercial tablets. Talanta. 2010;80:473-8.

74. Wang YF, Wu ZS, Wang ZY, Xu MF, Shi XY, Qiao YJ. Rapid analysis of spatial distribution of PVPP and hardness of Yinhuang dispersible tablets by NIR-Cl. J Innov Opt Health Sci. 2014;9:1550016.

75. Zhang Y, Xie YF, Song FR, Liu ZQ, Cong Q, Zhao B. Quantitative analysis of berberine in processed coptis by near-infrared diffuse reflectance spectroscopy. Chem Res Chin Univ. 2008;24:717-21.

76. Pei YL, Wu ZS, Shi XY, Zhou LW, Qiao YJ. Rapid assessment of critical quality attributes of Chinese Materia Medica (II): strategy of NIR assignment. Spectrosc Spect Anal. 2014;34:2391-6.

77. Esmonde-White KA, Cuellar M, Uerpmann C, Lenain B, Lewis IR. Raman spectroscopy as a process analytical technology for pharmaceutical manufacturing and bioprocessing. Anal Bioanal Chem. 2017:409:637-49.

78. Hu XH, Zhou JC. Applicationg and progress of Raman spectroscopy. Anal Instrum. 2011:6:1-4.

79. Wikström H, Romero-Torres S, Wongweragiat S, Williams JA, Grant ER, Taylor LS. On-line content uniformity determination of tablets using low-resolution Raman spectroscopy. Appl Spectrosc. 2006;60:672-81.

80. Desai D, Li D, Harianawala A, Sprockel O, Huang M, Timmins P. Solubilization of entecavir by povidone to overcome content uniformity challenges for low-dose tablet formulations. Pharm Dev Technol. 2013:18:1305-13.

81. Galeev RR, Semanov DA, Galeeva EV, Falaleeva TS, Aryslanov IR, Saveliev AA, Davletshin RR. Peak window correlation method for drug screening using Raman spectroscopy. J Pharm Biomed Anal. 2019;163:9-16.

82. Moriyama K, Takami Y, Uozumi N, Okuda A, Yamashita M, Yokomizo R, Shimada K, Egawa T, Kamei T, Takayanagi K. Assessment of drug content uniformity of atropine sulfate triturate by liquid chromatography-tandem mass spectrometry, X-ray powder diffraction, and Raman chemical imaging. J Pharm Health Care Sci. 2016;2:4.

83. Han S, Hasi W, Lin X, Lin S, Yang F, Lou XT, Lu ZW. Detection of cinnabars in mongolian medicines using Raman spectroscopy. Spectrosc Spect Anal. 2015;35:2773-5.

84. Busser B, Moncayo S, Coll JL, Sancey L, Motto-Ros V. Elemental imaging using laser-induced breakdown spectroscopy: a new and promising approach for biological and medical applications. Coord Chem Rev. 2018:358:70-9.

85. Liu XN, Wu ZS, Qiao YJ. Review on rapid evaluation of product quality attributes and application prospects in Chinese Materia Medica. World Chin Med. 2013:8:1269-72.
86. Myakalwar AK, Sreedhar S, Barman I, Dingari NC, Venugopal Rao S, Prem Kiran P, Tewari SP, Manoj Kumar G. Laser-induced breakdown spectroscopy-based investigation and classification of pharmaceutical tablets using multivariate chemometric analysis. Talanta. 2011;87:53-9.

87. Liu X, Zhang Q, Wu Z, Shi X, Zhao N, Qiao Y. Rapid elemental analysis and provenance study of Blumea balsamifera DC using laser-induced breakdown spectroscopy. Sensors. 2014;15:642-55.

88. Liu XN, Shi XY, Jia SY, Zhao N, Wu ZS, Qiao YJ. Rapid multi-elemental analysis on four precious Tibetan medicines based on LIBS technique. Chin J Chin Mater Med. 2015;40:2239-43.

89. Liu XN, Huang JM, Wu ZS, Zhang Q, Shi XY, Zhao N, Jia SY, Qiao YJ. Microanalysis of multi-element in Juncus effusus L. by LIBS technique. Plasma Sci Technol. 2015;17:904-8.

90. Liu XN, Ma Q, Liu SS, Shi XY, Zhang Q, Wu ZS, Qiao YJ. Monitoring As and $\mathrm{Hg}$ variation in An-Gong-Niu-Huang Wan (AGNH) intermediates in a pilot scale blending process using laser-induced breakdown spectroscopy. Spectrochim Acta A Mol Biomol Spectrosc. 2015;151:547-52.

91. Liu XN, Zheng QS, Che XQ, Wu ZS, Qiao YJ. Research on whole blending end-point evaluation method of Angong Niuhuang Wan based on QbD concept. Chin J Chin Mater Med. 2017:42:1083-8.

92. Wang JM, Xue SW, Zheng PC, Chen YY, Peng R. Determination of lead and copper in Ligusticum wallichii by laser-induced breakdown spectroscopy. Anal Lett. 2017;50:2000-11.

93. Wang JM, Liao XY, Zheng PC, Xue SW, Peng R. Classification of Chinese herbal medicine by laser-induced breakdown spectroscopy with principal component analysis and artificial neural network. Anal Lett. 2018;51:575-86.

94. Porizka P, Klus J, Kepes E, Prochazka D, Hahn DW, Kaiser J. On the utilization of principal component analysis in laser-induced breakdown spectroscopy data analysis, a review. Spectrochim Acta B. 2018;148:65-82.

95. Hancock BC, Mullarney MP. X-ray microtomography of solid dosage forms. Pharm Technol. 2005;29:92-100.

96. Liu RH, Yin XZ, Li HY, Shao Q, York P, He Y, Xiao TQ, Zhang JW. Visualization and quantitative profiling of mixing and segregation of granules using synchrotron radiation $\mathrm{X}$-ray microtomography and three dimensional reconstruction. Int J Pharm. 2013:445:125-33.

97. Lu XL, Zheng Q, Yin XZ, Xiao GQ, Liao ZH, Yang M, Zhang JW. Quantitative structure characteristics and fractal dimension of Chinese medicine granules measured by synchrotron radiation $\mathrm{X}$-ray computed micro tomography. Acta Pharm Sin. 2015;50:767-74.

98. Li H, Yin X, Ji J, Sun L, Shao Q, York P, Xiao T, He Y, Zhang J. Microstructural investigation to the controlled release kinetics of monolith osmotic pump tablets via synchrotron radiation $\mathrm{X}$-ray microtomography. Int J Pharm. 2012;427:270-5.

99. Wu L, Wang L, Wang S, Xiao T, Chen M, Shao Q, York P, Singh V, Yin X, Gu $J$, Zhang J. Three dimensional structural insight of laser drilled orifices in osmotic pump tablets. Eur J Pharm Sci. 2016;93:287-94.

100. Duan XH, Wu L, Li X, Zhang GQ, Li HY, Qin W, Yin XZ, Zhang JW. Threedimensional structure of beads self-assembled by cyclodextrin using synchrotron radiation X-ray microcomputed tomography. Acta Pharm Sin. 2018:53:291-6.

101. Zhang JW, Meng FY, Xiao TQ. Structure-based strategy for consistency evaluation of dosage forms. Acta Pharm Sin. 2017:52:659-66.

102. Kazemipour M, Ansari M, Ramezani H, Moradalizadeh M. Simultaneous determination of lovastatin and niacin in tablet by first and third derivative spectrophotometry and $\mathrm{H}$-point standard addition methods. Res Pharm Sci. 2012;7:95-102.

103. Zhu XR, Li N, Shi XY, Qiao YJ, Zhang ZY. Study on Chinese medicinal qingkailing injection intermediate by least squares support vector machines and ultraviolet spectrometry. Chin J Anal Chem. 2008;28:1626-9.

104. Al-Kindy SM, Suliman FE. Determination of ibuprofen in pharmaceutical formulations using time-resolved terbium-sensitized luminescence. Luminescence. 2007;22:294-301.

105. de Grazia U, D’Urso A, Ranzato F, De Riva V, Contarato G, Billo G, Perini F, Galloni E. A liquid chromatography-mass spectrometry assay for determination of perampanel and concomitant antiepileptic drugs in the plasma of patients with epilepsy, compared with a fluorescence hplc assay. Ther Drug Monit. 2018;40:477-85.

106. Alyami H, Dahmash E, Bowen J, Mohammed AR. An investigation into the effects of excipient particle size, blending techniques and 
processing parameters on the homogeneity and content uniformity of a blend containing low-dose model drug. PLOS ONE. 2017;12:e0178772.

107. Shawky E, Ibrahim RS. Bioprofiling for the quality control of Egyptian propolis using an integrated NIR-HPTLC-image analysis strategy. J Chromatogr B Anal Technol Biomed Life Sci. 2018;1095:75-86.

108. Wu ZS, Tao O, Cheng W, Yu L, Shi XY, Qiao YJ. Research on spatial distribution and composition uniformity of rukuaixiao tablets intermediate by spectral imaging. Chin J Anal Chem. 2011;39:628-34.

109. Wu ZS, Tao O, Cheng W, Yu L, Shi XY, Qiao YJ. Visualizing excipient composition and homogeneity of compound liquorice tablets by nearinfrared chemical imaging. Spectrochim Acta A Mol Biomol Spectrosc 2012;86:631-6.

110. Wu ZS, Tao O, Dai XX, Du M, Shi XY, Qiao YJ. Monitoring of a pharmaceutical blending process using near infrared chemical imaging. Vib Spectrosc. 2012;63:371-9.

111. Liu R, Sun Q, Hu T, Li L, Nie L, Wang J, Zhou W, Zang H. Multi-parameters monitoring during traditional Chinese medicine concentration process with near infrared spectroscopy and chemometrics. Spectrochim Acta A Mol Biomol Spectrosc. 2018;192:75-81.

112. Yang $Y$, Jin $Y$, Wu $Y$, Chen Y. Application of near infrared spectroscopy combined with competitive adaptive reweighted sampling partial least squares for on-line monitoring of the concentration process of Wangbi tablets. J Near Infrared Spectrosc. 2016;24:171-8.

113. Yang $Y$, Wang $L, W u Y, L i u X, B i Y$, Xiao W, Chen Y. On-line monitoring of extraction process of Flos Lonicerae Japonicae using near infrared spectroscopy combined with synergy interval PLS and genetic algorithm. Spectrochim Acta A Mol Biomol Spectrosc. 2017;182:73-80.

114. Li JJ, Liu JL, Jin RY, Tang YP, Yue SJ, Wang LW, Long X, Zhang GH, Meng $\mathrm{QH}, \mathrm{Li}$ RX. Quantitative measurement of artemisinin content in Chinese traditional compound medicine by Raman spectroscopy. Spectrosc Spect Anal. 2019;18:2403-8.

115. Yan X, Li W, Zhang X, Liu S, Qu H. Development of an on-line Raman spectral analytical method for monitoring and endpoint determination of the Cornu Caprae Hircus hydrolysis process. J Pharm Pharmacol. 2020;72:132-48.

116. Wang Y, Sun GX, Jin Y, Zhang J, Gao JY, Sabi-Mouka EMB. A comprehensive strategy to quantify the complex system by ultraviolet and infrared spectra analyses coupled with combustion heat for recognizing the quality consistency of San-Huang tablets. Am J Anal Chem. 2017:8:668-80.

117. Liang D, Yin YH, Miao LY, Zheng X, Gao W, Chen XD, Wei M, Chen SJ, Li $S$, Xin GZ, et al. Integrating chemical similarity and bioequivalence: a pilot study on quality consistency evaluation of dispensing granule and traditional decoction of Scutellariae Radix by a totality-of-the-evidence approach. J Pharm Biomed Anal. 2019;169:1-10.

118. Zhou W, Cai BC, Shan JJ, Wang S, Di L. Discovery and current status of evaluation system of bioavailability and related pharmaceutical technologies for traditional Chinese medicines-Flos Lonicerae Japonicae-Fructus Forsythiae Herb couples as an example. Int J Mol Sci. 2015;16:28812-40.

119. Xiao XH, Wang JB, Yan D. Studies and application of biological evaluation in the quality standardization of Chinese medicines. World Sci Technol Mod Tradit Chin Med. 2014;16:514-8. https://doi.org/10.11842/ wst.2014.03.011.

120. You Y, Liao FL, Huang LQ. Development of bioassay method in quality control of traditional Chinese medicine. Chin J Chin Mater Med. 2018:43:452-6.

121. Li HB, Yan D, Wang JB, Wang JY, Bei ZC, Wei L, Xiao XH. Biological evaluation of Radix Isatidis based on neuraminidase activity assay. Acta Pharm Sin. 2009:44:162-6.

122. Han B, Mao X, Han SX, Chen Y, Xiang YH, Ge YM, Liao FL, You Y. Antiplatelet aggregation bioassay based quality control for XST capsules. Chin J Chin Mater Med. 2015;40:4597-602.

123. Wu YS, Zhang Q, Jin C, Yan D, Liu Y, Xiang YH, Du XX, Wang J. Investigation on the bioactivity fingerprint of Qingkailing injection by microcalorimetry. Chin Pharm J. 2009:44:471-4.

124. Sha MC, Zhang HZ, He Q, Bi D, Qian JF, Wang JB, Xiao XH. Consistency evaluation method for Lianhua Qingwen Capsule based on microcalorimetry. Chin Tradit Herb Drugs. 2017;48:2202-6.

125. Sun WY, Tong L, Li DX, Bi KS. Bioactive consistency evaluation of cardiotonic pill using marker genes. Acta Pharm Sin. 2016;51:1290-6.
126. Kjelgaard-Petersen C, Siebuhr AS, Christiansen T, Ladel C, Karsdal M, Bay-Jensen AC. Synovitis biomarkers: ex vivo characterization of three biomarkers for identification of inflammatory osteoarthritis. Biomarkers. 2015;20:547-56.

127. O'Bryant SE, Mielke MM, Rissman RA, Lista S, Vanderstichele H, Zetterberg H, Lewczuk P, Posner H, Hall J, Johnson L, et al. Blood-based biomarkers in Alzheimer disease: current state of the science and a novel collaborative paradigm for advancing from discovery to clinic. Alzheimers Dement. 2017;13:45-58.

128. Prasse A, Pechkovsky DV, Toews GB, Schäfer M, Eggeling S, Ludwig C, Germann M, Kollert F, Zissel G, Müller-Quernheim J. CCL18 as an indicator of pulmonary fibrotic activity in idiopathic interstitial pneumonias and systemic sclerosis. Arthritis Rheum. 2007;56:1685-93.

129. Kurita KL, Glassey E, Linington RG. Integration of high-content screening and untargeted metabolomics for comprehensive functional annotation of natural product libraries. Proc Natl Acad Sci USA. 2015;112:11999-2004.

130. Zhou J, Wang W, Liu M, Liu Z. Molecular authentication of the traditional medicinal plant Peucedanum praeruptorum and its substitutes and adulterants by DNA—barcoding technique. Pharmacogn Mag. 2014;10:385-90.

131. Raveendar S, Lee JR, Park JW, Lee GA, Jeon YA, Lee YJ, Cho GT, Ma KH, Lee SY, Chung JW. Potential use of ITS2 and matK as a two-locus DNA barcode for identification of Vicia species. Plant Breed Biotechnol. 2015;3:58-66.

132. Liu ZW, Gao YZ, Zhou J. Molecular authentication of the medicinal species of Ligusticum (Ligustici Rhizoma et Radix, "Gao-ben") by integrating non-coding internal transcribed spacer 2 (ITS2) and its secondary structure. Front Plant Sci. 2019;10:429.

133. Feng $S$, Jiang $Y$, Wang $S$, Jiang $M$, Chen Z, Ying $Q$, Wang $H$. Molecular identification of Dendrobium species (Orchidaceae) based on the DNA barcode ITS2 region and its application for phylogenetic study. Int J Mol Sci. 2015;16:21975-88.

134. Zhang YM, Yan D, Zhang P, Ren YS, Zhang SF, Feng X, Xiao XH. Quality control of shuanghuanglian freeze-dried powder for injection based on its HPLC-ELSD fingerprints and biological profiles. Acta Pharm Sin. 2010;45:93-7.

135. Tilton R, Paiva AA, Guan JQ, Marathe R, Jiang Z, van Eyndhoven W, Bjoraker J, Prusoff Z, Wang H, Liu SH, et al. A comprehensive platform for quality control of botanical drugs (PhytomicsQC): a case study of Huangqin Tang (HQT) and PHY906. Chin Med. 2010;5:30.

136. Lam W, Ren Y, Guan F, Jiang Z, Cheng W, Xu CH, Liu SH, Cheng YC Mechanism based quality control (MBQC) for quality control of herbal products: a case study YIV-906 (PHY906). Front Pharmacol. 2018;9:1324.

137. Gong D, Hong Y, Sun G, Zhang J. Novel strategy for quality consistency evaluation of Chinese medicine "YIQING" tablet that combines the simultaneous quantification and screening of ten bioactive constituents. J Sep Sci. 2017:40:3064-73.

138. Zhang Y, Sun G, Hou Z, Yan B, Zhang J. Evaluation of the quality consistency of powdered poppy capsule extractive by an averagely linear-quantified fingerprint method in combination with antioxidant activities and two compounds analyses. J Sep Sci. 2017:40:451 1-20.

139. Xiong Y, Hu Y, Li F, Chen L, Dong Q, Wang J, Gullen EA, Cheng YC, Xiao $X$. Promotion of quality standard of Chinese herbal medicine by the integrated and efficacy-oriented quality marker of effect-constituent Index. Phytomedicine. 2018;45:26-35.

140. Dong $Q$, Wang JB, Zhang DK, Feng WW, Zhang CE, Niu M, Dong XP, Xiao XH. Uniformity of coptidis rhizoma decoction pieces dispensing based on effective constituent equivalence. Chin J Chin Mater Med. 2015;40:3981-6.

141. Zhang CY, Li XX, Li P, Jiang Y, Li HJ. Consistency evaluation between dispensing granule and traditional decoction from Coptidis Rhizoma by using an integrated quality-based strategy. Phytochem Anal. 2020. https://doi.org/10.1002/pca.2905.

142. Xiao XH, Wang JB, Liu CX. Biological assay for TCM quality control. Beijing: People's Medical Publishing House; 2017.

143. Bracewell-Milnes T, Saso S, Abdalla H, Nikolau D, Norman-Taylor J, Johnson M, Holmes E, Thum MY. Metabolomics as a tool to identify biomarkers to predict and improve outcomes in reproductive medicine: a systematic review. Hum Reprod Update. 2017;23:723-36. 
144. Wishart DS. Emerging applications of metabolomics in drug discovery and precision medicine. Nat Rev Drug Discov. 2016;15:473-84.

145. Qu TL, Wei YH, Li AP, Qin XM, Li ZY. 1H NMR fingerprints of Huangqi injection solution. Acta Pharm Sin. 2016;51:780-5.

146. Ma H, Zhou J, Guo H, Shang E, Zhu Z, Kuzmanov U. A strategy for the metabolomics-based screening of active constituents and quality consistency control for natural medicinal substance toad venom. Anal Chim Acta. 2018;1031:108-18.

147. Zhang Y, Yang L, Zhang J, Shi M, Sun G. Micellar electrokinetic capillary chromatography fingerprints combined with multivariate statistical analyses to evaluate the quality consistency and predict the fingerprint-efficacy relationship of Salviae miltiorrhizae Radix et Rhizoma (Danshen). J Sep Sci. 2017:40:2800-9.

148. Yang Z, Sun GX. Total detection of Tianma Toutong tablets for quality consistency by a five-wavelength fusion fingerprint and chemometrics. J Sep Sci. 2017:40:2703-12.

149. Cao B, Ci ZM, Xu RC, Feng B, Xu H, Du XJ, Zhang DK, Zhang HZ, Han L. Quality evaluation of Xiaojin Pills based on antiplatelet aggregation biological potency assay. Chin Tradit Herb Drugs. 2020;51:1251-6.

150. Chen S, Sun G, Ma D, Yang L, Zhang J. Quantitative fingerprinting based on the limited-ratio quantified fingerprint method for an overall quality consistency assessment and antioxidant activity determination of Lianqiao Baidu pills using HPLC with a diode array detector combined with chemometric methods. J Sep Sci. 2018;41:548-59.

151. Wang Y, Sun G, Liu Z, Liu Y, Gao Y, Zhang J, Ji Z, Chen X. Capillary electrophoresis fingerprinting coupled with chemometrics to evaluate the quality consistency and predict the antioxidant activity of Sanhuang tablet as part of its quality control. J Sep Sci. 2014;37:3571-8.

152. Ma D, Yang L, Yan B, Sun G. Capillary electrophoresis fingerprints combined with chemometric methods to evaluate the quality consistency and predict the antioxidant activity of Yinqiaojiedu tablet. J Sep Sci. 2017:40:1796-804.

153. Hou Z, Sun G, Guo Y, Yang F, Gong D. Capillary electrophoresis fingerprints combined with linear quantitative profiling method to monitor the quality consistency and predict the antioxidant activity of alkaloids of Sophora flavescens. J Chromatogr B Anal Technol Biomed Life Sci. 2019;1133:121827.

154. Liu Y, Sun G, Wang Y, Yang L, Yang F. Monitoring the quality consistency of Weibizhi tablets by micellar electrokinetic chromatography fingerprints combined with multivariate statistical analyses, the simple quantified ratio fingerprint method, and the fingerprint-efficacy relationship. J Sep Sci. 2015:38:2174-81.

155. Ji Z, Sun W, Sun G, Zhang J. Monitoring the quality consistency of Fufang Danshen Pills using micellar electrokinetic chromatography fingerprint coupled with prediction of antioxidant activity and chemometrics. J Sep Sci. 2016;39:3019-127.

156. Yang L, Xie X, Zhang J, Sun G. Microemulsion electrokinetic chromatography in combination with chemometric methods to evaluate the holistic quality consistency and predict the antioxidant activity of Ixeris sonchifolia (Bunge) Hance injection. PLoS ONE. 2016;11:e0157601.

157. Yang L, Sun G, Guo Y, Hou Z, Chen S. Holistic evaluation of quality consistency of Ixeris sonchifolia (Bunge) Hance injectables by quantitative fingerprinting in combination with antioxidant activity and chemometric methods. PLOS ONE. 2016;11:e0148878.

158. Wang F, Xiong ZY, Li P, Yang H, Gao W, Li HJ. From chemical consistency to effective consistency in precise quality discrimination of Sophora flower-bud and Sophora flower: discovering efficacy-associated markers by fingerprint-activity relationship modeling. J Pharm Biomed Anal. 2017;132:7-16.

159. Viapiana A, Struck-Lewicka W, Konieczynski P, Wesolowski M, Kaliszan R. An approach based on HPLC-fingerprint and chemometrics to quality consistency evaluation of Matricaria chamomilla L. commercial samples. Front Plant Sci. 2016;7:1561.

160. Chen J, Gao J, Sun G. Quantitative analysis combined with chromatographic fingerprint and antioxidant activities for the comprehensive evaluation of compound Danshen tablets. J Sep Sci. 2017:40:1244-53.

161. Chen S, Sun G, Yang L, Zhang J. Micellar electrokinetic chromatography fingerprinting combined with chemometrics as an efficient strategy for evaluating the quality consistency and predicting the antioxidant activity of Lianqiao Baidu pills. J Sep Sci. 2017:40:2838-48.

162. Yu Y, Gong D, Zhu Y, Wei W, Sun G. Quality consistency evaluation of Isatidis Folium combined with equal weight quantified ratio fingerprint method and determination of antioxidant activity. J Chromatogr B Anal Technol Biomed Life Sci. 2018;1095:149-56.

163. Zhang Y, Yang F, Zhang J, Sun G, Wang C, Guo Y, Wen R, Sun W. Quantitative fingerprint and quality control analysis of compound liquorice tablet combined with antioxidant activities and chemometrics methods. Phytomedicine. 2019;59:152790.

164. Dai TT, Yang FL, Liu JD, Sun GX. Evaluation of the quality consistency of Zhenju Jiangya tablets by systematic quantified fingerprint method in combination with antioxidant activity and three compounds analyses. Microchem J. 2019:150:104175.

\section{Publisher's Note}

Springer Nature remains neutral with regard to jurisdictional claims in published maps and institutional affiliations.
Ready to submit your research? Choose BMC and benefit from:

- fast, convenient online submission

- thorough peer review by experienced researchers in your field

- rapid publication on acceptance

- support for research data, including large and complex data types

- gold Open Access which fosters wider collaboration and increased citations

- maximum visibility for your research: over 100M website views per year

At $\mathrm{BMC}$, research is always in progress.

Learn more biomedcentral.com/submissions 